Document downloaded from:

http://hdl.handle.net/10251/145425

This paper must be cited as:

Robles Martínez, A.; Ruano García, MV.; Charfi, A.; Lesage, G.; Heran, M.; Harmand, J.; Seco Torrecillas, A.... (12-2). A review on anaerobic membrane bioreactors (AnMBRs) focused on

modelling and control aspects. Bioresource Technology. 270:612-626.

https://doi.org/10.1016/j.biortech.2018.09.049



The final publication is available at

https://doi.org/10.1016/j.biortech.2018.09.049

Copyright Elsevier

Additional Information 


\title{
A review on anaerobic membrane bioreactors (AnMBRs) focused on modelling and control aspects
}

Ángel Robles a, Maria Victoria Ruano a , Amine Charfi ${ }^{b}$, Geoffroy Lesage c, Marc Heran c, Jérôme Harmand d, Aurora Seco a, Jean-Philippe Steyer d, Damien J. Batstone e, Jeonghwan Kim ${ }^{f}$, José Ferrer $g$

a CALAGUA - Unidad Mixta UV-UPV, Departament d'Enginyeria Química, Universitat de València, Avinguda de la Universitat s/n, 46100, Burjassot, València, Spain

b LG-Hitachi Water solutions, B-1104 Daewoo Technopark, 261, Doyak-ro, Wonmi-gu, Bucheon-si, Gyeonggi-do, 14523, South Korea

c Institut Européen des Membranes, IEM - UMR 5635, ENSCM, CNRS, Univ Montpellier, Montpellier, France

d LBE, Univ Montpellier, INRA, 102 avenue des Etangs, 11100 Narbonne, France

e Advanced Water Management Centre (AWMC), The University of Queensland, QLD 4072, Australia fDepartment of Environmental Engineering, Inha University, Incheon, South Korea

g CALAGUA - Unidad Mixta UV-UPV, Institut Universitari d'Investigació d'Enginyeria de l'Aigua i Medi Ambient - IIAMA, Universitat Politècnica de València, Camí de Vera s/n, 46022, València, Spain.

\begin{abstract}
The use of anaerobic membrane bioreactor technology (AnMBR) is rapidly expanding. However, depending on the application, AnMBR design and operation is not fully mature, and needs further research to optimize process efficiency and enhance applicability. This paper reviews state-of-the-art of AnMBR focusing on modelling and control aspects. Quantitative environmental and economic evaluation has demonstrated substantial advantages in application of AnMBR to domestic wastewater treatment, but detailed modelling is less mature. While anaerobic process modelling is generally mature, more work is needed on integrated models which include coupling between membrane performance (including fouling) and the biological process. This should include microbial factors, which are important to generation of specific foulants such as soluble and particulate inert organics. Mature and well-established control tools, including better feedback control strategies are also required for both the process, and for fouling control.
\end{abstract}

\section{Keywords}

Anaerobic Membrane Bioreactor (AnMBR), Control, Fouling, Hydraulics, Modelling 


\section{Introduction}

\subsection{Circular Economy in waste treatment}

Economy models based on the extraction of non-renewable raw materials and transformations are characterized by unsustainability in the long-term, with this unsustainability increasing as world population increases. Water, food, and energy are three of the major resource issues facing humanity in many places around the world. The necessity of closing production cycles and enhancing resource sustainability is a driver to move towards a self-sufficient cradle-to-cradle bio-based economy (Puyol et al., 2017).

Increasing water stresses, the necessity of reducing carbon footprint and the increased depletion of resources such as fossil fuels or rare materials has boosted the necessity of applying a new development model focused on Circular Economy (CE). The adoption of the principles of CE would allow protecting businesses against scarcity of resources, developing an environmentally sustainable economy, and opening new markets, thus creating new jobs. CE aims at transforming non-renewable raw-material transformation economy models into a self-sufficient cradle-to-cradle bio-based economy, since the generated waste is considered a source of valuable resources. Hence, urban, agricultural, and industrial wastes are regarded as a raw material and not as a waste anymore.

Water stress is a serious problem worldwide. As a case in point, due to the extension of territory facing water scarcity problems in the European Union (EU), reclaimed water is a prominent issue in EU policy and can provide important environmental, economic and social benefits. Nevertheless, regulators and policy makers have an important role in ensuring the success of water reuse implementation around the world (Sgroi et al., 2018).

Nutrient recycling from waste to farmland is of great interest in CE, particularly phosphorus, because it is an essential element, irreplaceable in the production of crops. Several models predict that phosphorus production will start decreasing by 2035 since the continuous increase in population demand will exceed production (Cordell and White, 2013). In addition, nitrogen recovery for agricultural purposes can reduce worldwide production costs due to the energy demand of fertilizer production (Do Nascimento et al., 
2015).

Regarding carbon footprint, aerobic waste treatment is an energy-intensive activity. For instance, numerous studies are available in the literature related to the estimation and minimization of greenhouse gas (GHG) emissions from wastewater treatment (Hao et al., 2015; Mannina et al., 2016).

\subsection{The role of anaerobic membrane bioreactors in the Circular Economy}

With increasing concerns about the global energy crisis and climate change, the focus on waste treatment has also shifted towards developing more energy-efficient and cost-effective systems. In general, aerobic-based wastewater treatment is energy intensive because of the considerable energy demand required for organic matter oxidation (Lee et al., 2017). Moreover, aerobic systems produce large amounts of biosolids. Anaerobic digestion (AD) consumes less energy, since oxygen is not needed for the removal of organics, transforms biodegradable organics into the gaseous energy carrier $\mathrm{CH}_{4}$ and produces less biosolids to be handled. AD has the potential for nutrient and energy recovery (Batstone and Virdis, 2014) but can present some issues depending on the operating conditions (e.g. hydraulic retention time (HRT), temperature, etc.) and the waste to be treated (e.g. low-strength wastewaters, etc.) mainly due to the low growth rate of microorganisms and their sensitivity to process dynamics.

The combination of $A D$ and membrane technology is a promising solution for the treatment of different waste types (Becker et al., 2017; Dereli et al., 2012; Galib et al., 2016; Kamali and Khodaparast, 2015; Ozgun et al., 2013). This combination has an intrinsic advantage: the use of membranes for decoupling the solids retention time (SRT) from the HRT, and inherent retention of pollutant solids, generating a high quality effluent. Increased biomass retention compensates for reduced growth rates of anaerobic microbes, even at low temperature, favoring the application of anaerobic biotechnology to a wider range of environmental conditions (Stazi and Tomei, 2018).

\subsection{Anaerobic membrane bioreactor configuration}

A number of anaerobic membrane bioreactor (AnMBR) full-scale plants are currently used to treat industrial effluents (Dereli et al., 2012), while AnMBR for low-strength sewage wastewater treatment has been applied at pilot scale (Shin and Bae, 2018). Two main AnMBR configurations can be defined based 
on how the membranes are integrated with the bioreactor: sidestream and immersed (see Figure 1). The sidestream configuration is generally applied to the treatment of high-strength wastewaters (e.g. industrial wastewater). The immersed configuration is usually applied to the treatment of low-strength wastewaters (e.g. sewage).

In sidestream AnMBRs (see Figure 1a), the membrane is placed outside the reactor in a recirculation loop where the mixed liquor circulates at high velocity. The main advantage of sidestream configuration is that the surface of the membranes is physically cleaned due to the cross-flow across the membrane surface. However, high energy requirements are required to achieve the desired cross-flow velocities. In immersed (or submerged) AnMBRs (see Figure 1b), the membranes are directly immersed in the mixed liquor, involving lower energy requirements in comparison with sidestream configurations, since permeate is obtained by vacuum or is driven by gravity. Among others aspects, membrane fouling is controlled in immersed AnMBRs by biogas-assisted membrane scouring. The combination of sidestream approach and immersed configuration results in an AnMBR where the membrane is immersed in an external membrane tank (Figure 1c). This configuration minimizes membrane fouling by concentrating the highshear (and hence high energy) in a smaller dedicated membrane reactor. The use of different reactor types has been reported within membrane bioreactor systems (Dereli et al., 2012; Nelson et al., 2017; Ozgun et al., 2013; Shin and Bae, 2018), including upflow anaerobic sludge blanket (UASB), expanded granular sludge bed (EGSB), fluidized bed (FB), completely stirred tank reactor (CSTR), or hybrid reactors.

\subsection{Potentials and limitations of AnMBR technology}

AnMBR technology presents a number of advantages advantages, such as:

- Retains anaerobic microbes completely since the HRT and the SRT are uncoupled. This high-rate AD system prevents washout of the slow-growing methane-forming methanogens while reducing footprint.

- Allows ambient-temperature AD operation by increasing the SRT even at cold climates, is costeffective compared with elevated temperature competing high-rate processes and offers advantages in terms of economy, society and environment (Pileggi and Parker, 2017). 
- Leads to a lower amount of biosolids to dispose due to the low growth yield of the anaerobic biomass. Moreover, the long SRT improves the stabilization of the produced biosolids.

- Produces excellent permeate qualities because of micron level filtration of the effluent regardless its initial quality (including microbiological decontamination by removing bacteria, algae, various parasites and even viruses when appropriate membrane cut-off is implemented).

- Facilitates further tertiary treatments for removal of micropollutants by removing organics which could otherwise reduce effectiveness also in combination with other existing technologies such as nanofiltration or ozonation (Shi et al., 2017).

- Is not destructive of nutrients allowing for its recovery or direct reuse in effluent (e.g. struvite crystallization, microalgae cultivation, fertirrigation...) (D. J. Batstone et al., 2015a; Li and Wang, 2006).

- Transforms biodegradable organics into the gaseous energy carrier $\mathrm{CH}_{4}$, suitable for energy production. Indeed, AnMBR can be net energy producer even when treating low-strength wastewater at ambient temperature (McCarty et al., 2011; Smith et al., 2012). On the other hand, other intermediate products can be obtained by staging AnMBR operation, such as the gaseous energy carrier $\mathrm{H}_{2}$ or volatile fatty acids (Khan et al., 2016).

- Reduces GHG emissions by saving energy consumption and producing $\mathrm{CH}_{4}$ suitable for being used as energy source.

Nevertheless, AnMBR technology presents some issues that need to be further evaluated depending on the waste to be treated, with three of the key issues being:

- The concentration of methane dissolved in the effluent increases as the operating temperature decreases, being of great importance for operation in cold/mild regions (Crone et al., 2016). Besides energy recovery, this dissolved methane needs to be captured to avoid its stripping to the atmosphere in downstream open-air steps (Smith et al., 2012). 
- Membrane fouling and cleaning is a classical key issue in AnMBR technology (Aslam et al., 2017c, 2017b; Lin et al., 2013; Stuckey, 2012; Wang et al., 2014). Fouling reduces system productivity and increases chemical cleaning requirements, thus reducing membrane lifespan whilst increasing operating expenses.

- A post-treatment step may be needed for nutrient removal/recovery depending on the receiving water body. Different advanced techniques can be applied to this aim (D. J. Batstone et al., 2015a): (i) struvite precipitation; (ii) microalgae cultivation; (iii) anammox process for ammonia oxidation via nitrite; (iv) fertirrigation; (v) osmosis membranes; (vi) ion exchange, or (vi) microbial fuel cells (MFC) and microbial electrolysis cells (MEC).

The need to intensify and better operate AnMBR-based processes makes necessary to navigate different constraints limiting the widespread application of AnMBR as core technology for the treatment of different waste types, such as the key issues mentioned above. However, mathematical models and the derived control laws are generally poorly related to these constraints. In this respect, incorporating all these core issues within AnMBR modelling may allow extending the application of this technology by assessing the treatment capability of AnMBR technology in different scenarios, while providing a valuable tool for process control and optimization as well as further mechanistic understanding that would serve to address new challenges.

Hence, this paper aims at reviewing the state-of-the-art of AnMBR, focusing on modelling and control aspects. Additionally, this paper aims to outlook of existing challenges and future perspectives to improve modelling and control of AnMBR, also identifying current needs for helping the link between modelling and control in order to ease model implementation and evaluation of possible future constrains.

\section{Modelling of anaerobic membrane bioreactors}

Understanding and optimizing a complex system such as a MBR-based system can be difficult and time-consuming mainly because of the large number of sub-processes taking place simultaneously, which generally are highly dependent upon each other. The biological processes involved in AnMBR 
systems can be successfully modelled by using either single stage standard anaerobic models (Batstone et al., 2002) or plant-wide models (Barat et al., 2013; Zaher et al., 2007a). To model the filtration processes, several empirical/semi-empirical models have been proposed to express the relationship between sludge characteristics and/or operating conditions, and membrane fouling. Moreover, different integrated modelling approaches (i.e. biological + filtration processes) have been also proposed.

\subsection{Biological process modelling}

Anaerobic process modelling is a mature and well-established field that is largely guided by a mechanistic model structure defined by the understanding of underlying processes (D. J. Batstone et al., 2015b). Nevertheless, one possible issue on AD modelling deals with the selection and adaptation of models capable of reproducing the performance of new processes and applications such as AnMBR. Other issues to be considered when modelling AnMBR systems particularly for domestic sewage are competition between methanogens and sulfate-reducing organisms (SRO) for the available substrate, the loss of methane dissolved in the effluent, and in general, shifts in microbial community caused by membrane filtration.

\subsubsection{Anaerobic digestion models}

Selecting adequate complexity levels within $A D$ models is needed to provide a useful representation of the system while meeting the desirable modelling goal, such as understanding the metabolic pathways or evaluating effluent quality and biogas production and quality. If an excessively complex model is chosen in comparison with the objective of the study or the substrate to degrade, this can make parameter estimation difficult. For instance, modelling of low-strength wastewaters in AnMBRs for methane production and COD removal to meet effluent standards may require of a lower knowledge of the metabolic pathways for organics degradation than when modelling high-strength wastewaters, since low pH or ammonia inhibition is unlikely to be an issue. On the other hand, modelling the degradation of more complex substrates (e.g. food waste), or where sulfur is present could require an increase in complexity beyond currently available models.

Probably the most widely applied model in the scientific literature is the IWA ADM1 (Batstone et al., 
2002), which has been effectively applied for different purposes, including anaerobic units in wastewater treatment (Donoso-bravo et al., 2011). A wide variety of modifications to the ADM have been proposed literature depending on the purpose of the modelling task (Batstone et al., 2015b, Zaher et al., 2007). In contrast, reduced order models have been proposed AnMBRs for specific applications. The collection model BNRM2 proposed by Barat et al. (2013) incorporates a model for the anaerobic degradation of low-complexity organic matter such as low-strength wastewaters or sewage sludge. Based on this model, Ferrer et al. (2015) proposed a design methodology for AnMBR technology treating sewage for minimizing both capital expenditure and operating expenses. Pretel et al. (2015) used this model for evaluating the economic impact of combining a primary clarifier and a sidestream AD process with a mainline AnMBR.

Biological models applied to AnMBR may also take into account the effect of biochemical processes on membrane performance. Aquino and Stuckey (2008), for instance, highlighted the necessity of modelling soluble microbial products (SMP) and extracellular polymeric substances (EPS) in AD. This modelling approach is important specifically for AnMBRs due to the accumulation of SMPs inside the system, since SMPs are known to play an important role in membrane fouling (pore blocking) while affecting process performance (effluent quality) (Aslam et al., 2018; Stuckey, 2012). For instance, Benyahia et al. (2013) proposed the anaerobic model AM2b, which consists in a modification of the simple two-steps AM2 model (Bernard et al., 2001) including production and degradation pathways of SMPs. This mathematical model was mainly developed for control design purposes.

\subsubsection{Sulfate-reducing processes}

The competition between methanogens and SRO for the available substrate is especially important in AnMBR systems treating wastewaters with low organic matter to sulfate ratios (COD:SO $4-S)$ (see e.g. Giménez et al., 2011). This includes domestic wastewater, since while the strength is low, the COD:S ratio is also generally low (Batstone, 2006). Moreover, simulating sulfate-reducing processes is essential for evaluating the feasibility of AD processes, since sulfate reduction to sulfide causes several technical problems (reduction of the quantity and quality of the biogas,toxicity, corrosion in pipes, etc). 
Although sulfate reduction is not incorporated in the model ADM1, it has been implemented several times as a side or main process. Figure 2 shows a schematic representation of the biochemical processes included in the model ADM1, including the sulfate-reducing processes modelled by different authors at different complexity levels. For instance, simple models that allow to simulate the competition between methanogens and SRO for acetate (Fomichev and Vavilin, 1997), acetate and hydrogen (Harerimana et al., 2013) or hydrogen (Batstone, 2006) have been proposed. Considering more SRO pathways, Frunzo et al. (2012) proposed a model to simulate gas-lift type reactors fed with $\mathrm{H}_{2}$ and $\mathrm{CO}_{2}$, including five groups of microorganisms: heterotrophic SRO, autotrophic SRO, homoacetogenic bacteria, methanogenic archaea, acetate-degrading bacteria. Up to four groups of SRO consuming butyrate, propionate, acetate and hydrogen have been also incorporated in ADM1 (Ahmed and Rodríguez, 2018; Barrera et al., 2015; Fedorovich et al., 2003), or in a plant-wide model (Durán, 2013; Durán et al., 2017).

Regarding the selection of model complexity for sulfate reduction, Ahmed and Rodríguez (2018) evaluated the complexity of five ADM1-based model structures differing in the number of SRO groups considered based on the electron donors used. The results highlighted that it is possible to simulate the AD of cane molasses vinasse only considering acetate utilizing and hydrogen utilizing $\mathrm{SRO}$, highlighting that complex model structures are required only in specific cases. Also in this way, Durán (2013) and Durán et al. (2017) modelled the performance of an AnMBR treating sulfate-rich sewage. Due to the reduced complexity of the substrate to consume, two groups of SRO (heterotrophic SRO growing on both VFA (propionate) and acetate, and autotrophic SRO growing on hydrogen) were enough for fitting the experimental data obtained at both steady- and unsteady-state conditions.

\subsubsection{Dissolved methane emissions}

$A D$ models allow the amount of methane dissolved in the effluent to be assessed, facilitating the design and selection of suitable approaches for dissolved methane capture. This is normally using a single controlling film dynamic gas-transfer equation with the gas-transfer coefficient $k\llcorner a$ being the dynamic parameter. Several approaches have been proposed in the literature to capture the dissolved methane from anaerobic effluents (Crone et al., 2016). Especially, degasification using non-porous 
membranes and micro-porous membrane contactors have been reported as a promising technology for dissolved methane recovery (Cookney et al., 2016; Crone et al., 2016; Henares et al., 2016). These membranes allow direct demethanization of anaerobic streams with positive energy balances of the separation process (Cookney et al., 2016; Henares et al., 2017). These also can be effectively modelled using standard chemical engineering principles.

Other cost-effective techniques are available for methane removal. Sánchez-Ramírez et al. (2015) and Pelaz et al. (2018) evaluated the efficiency of using dissolved methane as electron donor for denitrification in the post-treatment of AnMBR effluents, achieving high removal rates. Chen and Smith (2018) used Microbial fuel cells (MFCs) for recovering the methane dissolved in the effluent of a mainstream AnMBR in order to recover energy and prevent GHG emissions.

\subsubsection{Shifts in microbial community caused by membrane operation}

Despite the maturity of $A D$ modelling, microbial ecology modelling is still developing because of new insights provided by modern molecular tools. The incorporation of membranes in an AD process results in substantial changes microbial community, with differences between bulk and membrane biofilm microbial ecology and the retention of niche microorganisms which would otherwise be washed-out (Skouteris et al., 2012).

The majority of work on assessing the microbial community on AnMBRs has been done using fingerprinting techniques or next-generation sequencing (NGS). These techniques have identified the key aceticlastic methanogen as Methanosaeta, with hydrogenotrophic methanogens being predominantly from Methanobacteriales or Methanomicrobiales (Gao et al., 2010; Padmasiri et al., 2007). Padmasiri et al. (2007) found relatively rapid shifts, on the order of 30 days from Methanosarcina to Methanosaeta based on loading conditions (increased loading resulted in an increase in Methanosaeta). Gao et al. (2010) analyzed multiple fractions in an artificial sewage based MBR (protein based feed). They were able to identify that fouling had a higher composition of specific species from OP11 (OP11-C13) and Deferribacteres, while the bulk was dominated by Bacteriodetes and Firmicutes (and Methanosaetaceae). These results indicate that biofouling is a more complex mechanism than simple 
cake formation.

The performance and microbial communities in a bioaugmented AnMBR (B-AnMBR) treating pharmaceutical wastewater was compared to a control AnMBR (C-AnMBR) (Ng et al., 2015). Pyrosequencing analysis showed that marine bacterial species (Oliephilus sp.) and halophilic bacterial species (Thermohalobacter sp.) were only present in the B-AnMBR, being these species identified as degraders of complex and recalcitrant organic matter and withstand hypersaline environments. Compared to a control AnMBR (C-AnMBR), genus Methanosaeta and Methanolobus were identified as dominant methanogens in the C-AnMBR and the B-AnMBR, respectively. Wu et al. (2017) evaluated the influence of salinity and cytostatic drugs on the microbial community in forward AnMBRs. The authors observed a decrease in the abundance of genes involved in methanogenesis as salinity increased. Muñoz Sierra et al. (2018) also observed a long-term shift microbial community in response to salinity changes in an AnMBR treating phenolic wastewater. Microbial community was dominated by bacteria belonging to the Clostridium genus and archaea by Methanobacterium and Methanosaeta genus. Syntrophic phenol degraders, such as Pelotomaculum genus were also found.

Seib et al. (2016) evaluated the influence of inflow microbiota and temperature on an AnMBR treating municipal wastewater. In response to temperature, Illumina sequencing revealed variations in bacterial communities while activity assays revealed that hydrogenotrophic methanogenesis was the main methanogenic pathway. In response to inflow, continual seeding with inflow microbiota shifted microbial communities to influent microbiota. Therefore, feeding changes also can result in a significant effect on the performance of AnMBR systems due to a shift in microbial ecology. Zamorano-López et al. (2018) observed notorious changes in microbial communities after feeding food waste as co-substrate to an AnMBR system normally operated treating sewage. The analysis of microbial population showed a microbial shift towards the dominance of Chloroflexi, Firmicutes, Synergistetes and Proteobacteria phyla once the system treated sewage jointly with food waste. The relative abundance of these potential hydrolytic phyla increased as the fraction of food waste fed to the system was increased. Durán et al. (2018) evaluated the performance of an AnMBR treating sewage jointly with food waste via model 
simulation and characterization of the microbial population dynamics through Illumina sequencing. The authors observed an increased hydrolytic activity due to the co-digestion of food waste with urban wastewater, observing furthermore a 3-fold increase of Archaea population and a significant raise of Levilinea genera. The feed of food waste also modified the most abundant sequences identified during the joint treatment, observing the appearance of new genera characterized by anaerobic fermentation of amino acids (Leptolinea, Aminomonas and Aminobacterium) over an extended period.

\subsection{Filtration process modelling}

Several (semi-)empirical models have been proposed (Naessens et al., 2012; Zuthi et al., 2012) to express the effect of bulk characteristics and/or operating conditions on membrane fouling propensity. The Carman-Kozeny equation, Darcy's law, and the resistance-in-series concept are the modelling approaches most commonly used. Classically, these modelling approaches have been developed for aerobic MBRs, although most of them can be adapted or applied in other MBR-based systems as AnMBRs.

\subsubsection{Pore blocking law models}

The pore blocking law models are based on four models describing separately four fouling mechanisms, the pore constriction (internal fouling), the complete blocking, the intermediate blocking and the cake formation. These models were derived also to express TMP variation for constant permeate flux. They have been widely considered to simulate fouling in MBRs (Charfi et al., 2012; Drews et al., 2009; Zheng et al., 2018). Wu et al. (2011) associated each fouling mechanism to a different foulant material found in MBRs, based on particle or molecular size. Suspended solids were associated to cake formation mechanism, colloidal material to complete blocking and soluble matter to pore constriction. Nevertheless, the hypothesis considered in pore blocking laws present some limitations such as considering straight and cylindrical pores as well as the absence of any phenomenon which counterbalance the convective forces towards the membrane. They also neglect the effect of mechanisms occurring simultaneously. Therefore, many works have attempted to improve those models by adapting them to cross-flow filtration mode and considering the shear effect on fouling control due to feed solution recirculation in the vicinity 
of membrane (De Bruijn et al., 2005; Field et al., 1995). Chellam and Cogan (2011) improved the cake formation model by including cake compressibility. For more realistic fouling simulation, the pore blocking law models have been combined to consider simultaneous fouling mechanisms (Bolton et al., 2006; Iritani and Katagiri, 2016).

\subsubsection{Resistance-in-series models}

Resistance-in-series models describe the flux through each in-series medium using Darcy's law for filtration. The resistance-in-series models have been adopted to consider the simultaneous effect of different fouling mechanisms, which is more realistic than one fouling mechanism model (pore blocking laws). The main mechanisms considered have been pore constriction due to internal fouling, pore blocking, and cake building. The internal fouling resistance is assumed proportional to the mass of soluble matter accumulated within the membrane pores as a result of their adsorption and desorption on the pore walls (Katsoufidou et al., 2005). The pore blocking resistance is assumed proportional to the variation of free membrane pores or the free membrane area (Charfi et al., 2018b). While some models consider the continuous increase of pore blocking mechanism during the filtration process (Charfi et al., 2017b), other models assume the pore blocking mechanism, hindered by the cake layer development which would serve as a second layer able to reject foulants and to prevent them to reach membrane pores entries (Katsoufidou et al., 2005; Wu et al., 2011). The cake resistance is usually calculated by multiplying the cake mass and the specific cake resistance (Charfi et al., 2014). In MBR the cake layer is mainly composed of suspended solids and soluble microbial products (SMP) (Gao et al., 2010; Lin et al., 2011). Nevertheless, in the majority of MBR processes with either immersed or external configurations, the cake development is controlled by shear forces in the vicinity of membrane surface created by aeration, gas bubbling, fluidized solid media and/or bulk recirculation. Cross flow filtration mode rather than dead-end filtration is more appropriate for AnMBRs since the cake detachment effect due to the shear forces can been added for cake mass estimation (Charfi et al., 2015).

The specific cake resistance can vary for a compressible deposit such as sludge, and it has been usually expressed as a function of the cake porosity using Kozeny-Carman equation (Charfi et al., 
2017b). For more accurate fouling modelling in MBR, the resistance due to the biofilm development is also considered. Chellam and Cogan (2011) developed a resistance-in-series model considering pore blocking by individual cells, cake formation, bacterial secretion of exopolymers and the non-uniform spatial deposition of foulants. Robles et al. (2013d) developed a model adapted to immersed MBRs taking into account the effect of biogas sparging as well as back-flushing on cake detachment to quantify the resistance of irreversible fouling widely encountered in MBR processes. Indeed, the main influential factor of this model was related to irreversible fouling formation (Robles et al., 2014a). This model was validated in an AnMBR system equipped with industrial-scale membranes in the short- (Robles et al., 2013d) and the long-term (Robles et al., 2013e).

\subsubsection{Critical-flux models}

The concept of critical flux introduced by Field et al. (1995) to define the flux beyond which, the fouling layer increases over time. Below critical flux, the fouling layer depth is stable, with particle deposition rate matched by particle crossflow shear. This concept helps to define the optimal operating conditions to enable stable operation. Fouling does occur below critical flux, mainly due to pore fouling and cake compression (resulting in cake heterogeneity). Fouling occurs in two steps, the first revealed by a slight and slow TMP increase followed by a sudden TMP jump due to the fouling layer inhomogeneity leading to a redistribution of the flux on the membrane surface. Based on this hypothesis, Ognier et al. (2004) developed a model to simulate the TMP and the local flux variations in an MBR operating at a constant flow rate.

\subsubsection{The role of the hydraulic environment}

\subsubsection{Fluid dynamics}

Computational fluid dynamics can determine a number of important factors which are difficult or unable to be measured, including internal flow distribution and membrane shear rate. Computational fluid dynamics (CFD) has been applied for modelling different systems aimed at producing biomethane and biohydrogen through biochemical conversion (Wu, 2013).

Böhm et al. (2012) highlighted the importance of multiphase fluid dynamics for membrane fouling 
mitigation by gas sparging. Nonetheless, the effects of gas scouring are still not completely understood due to the complex hydrodynamic interactions between orthogonal and crossflows and turbulent eddies created by bubbling. In this respect, Boyle-Gotla et al. (2014) predicted membrane shear effects by gas sparging in an AnMBR system equipped with flat-sheet membranes. To this aim, a CFD model based on a two fluid (Eulerian-Eulerian) approach was used to model liquid and gas phases simultaneously. The model showed the potential for analysis of non-uniform membrane surface shearing, prediction of critical flux, and design and optimization purposes. Trad et al. (2015) optimized the hydrodynamics and mixing in an AnMBR consisting in a mechanically-stirred tank linked to an external hollow-fiber microfiltration (MF) membrane module operating in the tangential "outside-in" crossflow mode (laced in a forced circulation loop). The computational strategy used in this study combined 1D and 3D CFD methodologies, including single-phase and two-fluid CFD models. The simulations predicted mixing time, the formation of a vortex, and the suspension of solids, providing necessary information for scaling-up purposes.

\subsubsection{Biogas sparging}

Biogas sparging is widely applied in AnMBR to control membrane fouling. The two-phase flows of gas and liquid can create instability along the membrane to disturb concentration-polarization layer or cake layer formation on membrane. The flow patterns in two-phase flow are often determined by a function of superficial liquid velocity $\left(U_{L}\right)$ and the relative ratio of gas/liquid velocity $\left(U_{G} / U_{L}\right)$ (Wibisono et al., 2014). The slug bubbles are known to produce longer wake regions which create stronger secondary flows and more local mixing on membrane than other types of gas bubbles (Wibisono et al., 2014). In AnMBRs with biogas sparging, the flow pattern is most likely bubble flow and/or slug flow due to the low gas flow rates required. The slug flow occurs when the gas phase moves as bulletin-shaped approaching the channel size of membrane and this bubble pattern has been known as being most effective to control membrane fouling (Cui et al., 2003). If gas/liquid ratio is too high, annular flow pattern would be dominant, with lower fouling reduction efficiency. As bubbles rise through a stagnant liquid containing impurities or contaminants in immersed AnMBRs, shear forces move these impurities into the wake region of bubble. However, there is no beneficial effect on reducing membrane fouling as the length of slug flow is longer 
than the critical length due to the limitation of size of wake region (Cui et al., 2003).

Although many studies indicated that bubble-induced fouling reduction efficiency is related to gasliquid flow ratio, channel diameter and liquid velocity, information on predicting the bubble-induced shear stress on membrane in AnMBR system is still very limited. Under biogas sparging, colloidal materials can be migrated preferentially towards the membrane due to particle size segregation driven by shearinduced diffusion (Jeison et al., 2009). Reducing particle size enhances the release of extracellular polymeric substances, thereby increasing fouling rate. Zhang et al. (2017a) observed that viscosity, sizes of suspended particles increased with decreasing in sparging rate. However, opposite results were observed with supracolloidal particles since soluble microbial products, proteins and carbohydrates and EPS concentrations decreased with decreasing sparging rate.

The effect of biogas sparging on fouling rate is dependent upon mixed liquor suspended solids concentration. Mahmoud and Liao (2017) found that critical flux increased with increased biogas sparging until reaching a critical biogas sparging rate. Similarly, increasing in MLTS decreased critical flux until reaching a critical MLTS concentration. Fox and Stuckey (2015) examined the existence of "critical sparging rate" above which there is no beneficial effect of increasing sparging rate. These findings are similar to the role of air sparging in fouling control with an aerobic immersed MBR system. With gas sparging, the permeate flux is relatively insensitive to the liquid flow rate over much of laminar flow region. This is because the secondary flow caused by bubbles is more dominant than the liquid flow on membrane (Cui et al., 2003).

\subsubsection{Cross-flow velocity}

Tangential flow rate in crossflow filtration serves to cause a hydraulic scouring effect on membrane with consequent reduction in fouling layer depth. Under crossflow, the concentration polarization layer is dispersed away from the membrane surface toward the bulk suspension. In crossflow filtration, particle transport is dependent on two mechanisms, dispersion caused by crossflow, and movement towards the membrane, caused by convective flux and surface interactions. Dispersion away from the membrane (or across the membrane) consists of Brownian diffusion (for particles bellow $1 \mu \mathrm{m}$ ), shear-induced diffusion 
and lateral migration (Choo and Lee, 1998). Brownian diffusion dominates the back transport of very small particles, whereas shear-induced dispersion dominates the transport of larger particles. Choo and Lee (1998) observed that hydrodynamic factors greatly affected the initial behavior of cake layer formation, but surface interactions should be considered more significant as particles approach the membrane surface. Hu et al. (2017) found that increasing crossflow velocity enhanced biodegradability of organic compounds in the AnMBR treating antibiotic solvent contained wastewater. However, the EPS concentration in membrane biofilm increased with cross-flow velocity, which is a negative impact in the longer time due to its role in compaction and adhesion. In addition, surface and particle interactions needs further investigation considering the wide variety of surface properties and particle size distributions.

\subsubsection{Particle scouring}

Recently, there has been upsurge of interests in adding scouring agents into the AnMBR to reduce membrane at relatively low energy consumption. Granular activated carbon (GAC) or powdered activated carbon (PAC) particles have been widely applied as scouring agents to induce mechanical cleaning effect on membrane (Hu and Stuckey, 2007; J. Kim et al., 2011). Here, GAC particles were fluidized along membrane by bulk flow only recirculated through AFMBR. The GAC particles fluidized can provide high surface area for biofilm formation and physical scouring membrane under which the alerted hydrodynamic condition might enhance shear rate for fouling mitigation (Charfi et al., 2017a).

The main objective of mechanical cleaning associated with particle scouring is to increase the shear stress in the vicinity of the membrane surface and create a scouring effect capable of detaching the foulants from the membrane. Scouring mechanisms driven by particle movement was based upon the momentum transferred from GAC particles acting on foulants (Aslam et al., 2017a; Aslam and Kim, 2017). Huang et al. (2008) considered that the sludge particles transport depends on two actions: the inertial lift force and the permeation drag force. They assumed that at steady state, the inertial lift velocity is equal to permeation flux, with particles having a diameter less than the critical diameter can deposit on the membrane surface. When adding the fluidization media, the critical diameter value will decrease. $\mathrm{A}$ 
model able to determine the deposit mass variation was then proposed. It includes the positive scouring effect of the fluidized particles and the negative sludge breakage effect on membrane resistance variation. This model highlights the effects of fluidized media size and dose.

In literature, many models were proposed to highlight the shear effect on cake resistance mitigation. Some models considering shear effect in MBRs are the ones proposed by Wu et al. (2011), Field et al. (1995), Li and Wang (2006) or Charfi et al. (2015), shown in Equations 1 to 4, respectively.

$$
\begin{aligned}
& \frac{\mathrm{dR}_{\mathrm{c}}}{\mathrm{dt}}=\mathrm{f}_{\mathrm{s}} \alpha \mathrm{J}_{\mathrm{p}} \mathrm{X}(E q \cdot 1) \\
& -\frac{1}{\mathrm{~J}_{\mathrm{p}}^{2}} \frac{\mathrm{dJ}_{\mathrm{p}}}{\mathrm{dt}}=\frac{\alpha \mathrm{X} \mathrm{J}_{\mathrm{p}}}{\mathrm{J}_{0} \mathrm{R}_{0}}-\frac{\alpha \tau}{\mathrm{J}_{0} \mathrm{R}_{0}}(E q .2) \\
& \frac{\mathrm{dm}_{\mathrm{c}}}{\mathrm{dt}}=\left(\frac{\mathrm{F}_{\mathrm{a}}}{\mathrm{F}_{\mathrm{a}}+\mathrm{F}_{\mathrm{l}}} \mathrm{J}_{\mathrm{p}} \mathrm{C}\right)-\left(\frac{\beta\left(1-\mathrm{K}_{\mathrm{ST}}\right) \mathrm{G} \mathrm{m}_{\mathrm{c}}^{2}}{\gamma \mathrm{V}_{\mathrm{f}}+\mathrm{m}_{\mathrm{c}}}\right)(E q .3) \\
& \frac{\mathrm{dm}_{\mathrm{c}}}{\mathrm{dt}}=\mathrm{J}_{\mathrm{p}} \cdot(\sigma \cdot \mathrm{S}+\mathrm{X}) \cdot\left(1-\beta m_{c}\right)(E q \cdot 4)
\end{aligned}
$$

Where, $F_{a}$ : drag force by suction; $F_{1}$ : lifting force; $f_{s}$ : suspended solids fraction that form cake; $G$ : shear intensity $\left(\mathrm{s}^{-1}\right)$; Jo: initial permeate flux; $\mathrm{J}_{\mathrm{p}}$ : permeate flux $\left(\mathrm{m} . \mathrm{s}^{-1}\right)$; $\mathrm{K}_{\mathrm{sT}}$ : stickness of biomass particles; $\mathrm{m}_{\mathrm{c}}$ : cake mass $\left(\mathrm{kg} \cdot \mathrm{m}^{-2}\right)$; Ro: membrane intrinsic resistance $\left(\mathrm{m}^{-1}\right)$; S: soluble microbial products concentration $\left(\mathrm{kg} \cdot \mathrm{m}^{-3}\right) ; \mathrm{X}$ : suspended solids concentration $\left(\mathrm{kg} \cdot \mathrm{m}^{-3}\right) ; \mathrm{V}_{\mathrm{f}}$ : permeate volume $\left(\mathrm{m}^{3} \cdot \mathrm{m}^{-2}\right) ; \mathrm{a}$ : specific cake resistance $\left(\mathrm{mkg}^{-1}\right)$; $\beta$ : erosion rate coefficient; $\mathrm{:} \mathrm{cake} \mathrm{compression} \mathrm{coefficient}\left(\mathrm{kg} \cdot \mathrm{m}^{-3} \cdot \mathrm{s}^{-1}\right) ; \sigma$ : fraction of soluble products rejected by membrane; $\mathrm{T}$ : cake erosion rate per unit area $\left(\mathrm{kg} \mathrm{m}^{-2} \mathrm{~s}^{-1}\right)$.

Wu et al. 2011 proposed a simple model assuming shear effect by considering only a fraction of suspended solids $\mathrm{f}_{\mathrm{s}}$ that deposit to form the cake (Eq. 1). The presented models (Eq. 2-4) assume the resulting cake resistance as the difference between the resistance created by matter deposited on the membrane surface by permeation force and the resistance reduced by detaching the matter from membrane surface by shear effect. Those models would be useful to describe the scouring effect created by fluidized media in particle sparging based AnMBRs. A comparative study with AFMBR using different types of fluidized media showed that, for the fresh GAC, the energy requirement for fluidization increased with size, but smaller sizes led to greater reduction in membrane fouling (Aslam et al., 2014). A 
mathematical model was developed to address fouling mitigation mechanisms in an AFMBR system using two types of non-adsorbing media including silica and polyethylene terephthalate (PET) beads (Charfi et al., 2018b). The model was developed by assuming two fouling mechanisms (1) pore blockage lead to the decrease in membrane surface porosity and (2) the progressive development of compressible cake layer on the membrane surface. The model also assumed that the suspended solids and the soluble microbial product would be the only foulants responsible for membrane performance. The model predicted that a media dosage of $50 \%(\mathrm{v} / \mathrm{v})$ was most effective in fouling reduction. A higher scouring effect on reducing both pore blockage and cake formation was obtained by the fluidized media having bigger size that had relatively lower density.

\subsection{Integrated modelling}

MBR-based systems are complex systems where variations in one phase (gas, liquid, and cake) can affect the performance of different processes (e.g. biochemical, filtration, hydrodynamics). Component models can be adapted and combined, resulting in integrated models capable of predicting the behavior of the system more accurately for design, diagnosis or optimization of the process.

\subsubsection{Combined biological and filtration models}

For more accurate assessment of fouling and better fouling control, integrated models combining single biological and filtration models have been developed. Numerous attempts have been done in aerobic MBR combining ASM models and resistance-in-series models. This is not common for anaerobic MBRs (Charfi et al., 2017b, 2018a). One example is the combination of the anaerobic model AM2b (Benyahia et al., 2013) and a resistance-in-series filtration model. Reasonable predictions were obtained using this integrated model (Charfi et al., 2017b) but more complete results would be reached with more complex biological models such as ADM1 model which could include SMP dynamics, as presented in Figure 3. As discussed previously, this is a particularly important aspect for AnMBRs, due to the long SRTs. Taking into account the shear effect of gas bubbling or fluidized media, the cake detachment could be considered, depending on the shear rate, accumulation of SMP (due to concentration polarization) and particulate inerts within the cake (depending on membrane characteristics), and the cake specific 
resistance. The role of SMP and colloids in membrane pore fouling could also be considered.

\subsubsection{Combination with other models}

Mathematical modelling of environmental impacts such as GHG emissions at a plant-wide scale allows understanding and managing impacts related to waste treatment and identifying research gaps (Longo et al., 2016; Mannina et al., 2016) . Different studies combining process modelling and life cycle assessment (LCA) are available in the literature dealing with the assessment of environmental impacts of AnMBR technology.

Smith et al. (2014) compared AnMBRs to different aerobic-based wastewater treatment plants (WWTPS) combining GPS-X (Hydromantis, Inc.) and LCA, showing that AnMBRs offer the potential for recovering more energy in the form of methane than conventional WWTPS. However, these authors identified a possible counterbalance of the energy recovered by AnMBR due to possible high-energy requirements for membrane operation. Pretel et al. (2015b) combined the model BNRM2 and LCA for elucidating how detailed design and operational decisions of immersed AnMBRs influence environmental, economic, and technological trade-offs across life cycle. These authors highlighted the necessity of optimizing design and operational conditions for achieving net energy positive AnMBRs contributing to the pursuit of carbon footprint. On the other hand, Pretel et al. (2016b) compared different aerobic-based WWTPs to AnMBR coupled to a post-treatment for nutrient removal. In this case, AnMBR combined with a CAS-based post-treatment resulted in significant reductions in different environmental impact categories mainly due to reduced power requirements. Becker et al. (2017) compared co-management of domestic wastewater and food waste using AnMBR and aerobic-based technologies. The results illustrated that AnMBR and high-rate activated sludge (HRAS) combined with AD were the most attractive scenarios because of energy recovery as methane. Pretel et al. (2016a) also highlighted the potential of AnMBR for the co-digestion of sewage and food waste. However, fugitive emissions of methane dissolved in the effluent severely increased global warming impacts related to AnMBR, highlighting the necessity of recovering this compound from the effluent. Cashman et al. (2018) evaluated the energy and GHG life cycle assessment of aerobic MBRs and AnMBRs, identifying that MBRs represent a promising 
technology for decentralized wastewater treatment and that psychrophilic AnMBR can result in net energy benefits. Another interesting combination is the integrated modelling of biological, filtration and energy processes. In this respect, Pretel et al. (2016c) proposed a plant-wide energy model for wastewater treatment plants, which was applied to an AnMBR system treating sewage at steady- and unsteady-conditions.

\subsection{Perspectives on process modelling}

Although AD modelling is a mature field, further work is needed to adequately evaluate the feasibility of different AD models for representing the performance of different AnMBR configurations (reactor type, filtration mode) treating different substrates (solid waste, low-strength wastewater, high-strength wastewater, sulfate) under different environmental conditions (cold/mild/warm/hot temperature conditions) for different modelling targets. One key issue is determination of biological complexity, (particularly inclusion of alternative electron sinks such as sulfate) depending on modelling goal. Hence, evaluating the accuracy of selected modelling approaches depending on modelling target would provide model developers and users with better information to decide on the optimum degree of complexity.

Changes in microbial ecology due to changes in AnMBR operation and configuration also highlights the necessity of pursuing the development of mathematical models to describe microbial behavior and interactions, dynamically, spatially and across scales (Wade et al., 2016). Indeed, modelling shifts in microbial community caused by membrane filtration would allow better understanding of the performance of AnMBRs under different operating and environmental conditions. However, this task can result in metabolic models that appear too complex, abstract or distant from practice. Metabolic models entail a great deal of mechanistic detail, which also requires significant computation demands, and a higher parameter estimation load. On the other hand, ecological models help elucidate microbes trends but they provide limited mechanistic detail. Hence, a benchmark modelling framework could be needed to adequately combining shifts observed on microbial ecology with phenomenological models that are less time demanding than metabolic ones, providing therefore insights into community dynamics and the roles of given species within those dynamics. 
It is widely accepted that the methane dissolved in the effluent must be recovered for further enhancing the economic and environmental feasibility of AnMBRs, especially when operating at low temperature and low HRTs. As noted above, methane recovery can be achieved through membranebased techniques such as degasification non-porous membranes and membrane contactors. These systems can be modelled through a resistance-in-series model considering liquid resistance, membrane resistance and gas resistance (or controlling resistance in the case of sparingly soluble gases) (Cookney et al., 2016). The model structure and parameters can consider contributions of different factors, including circulation regime of gas and liquid, the membrane material, the transmembrane pressure, etc.

Regarding membrane filtration, process modelling might provide insights regarding key factors playing a major role in fouling, providing therefore helpful data for the diagnosis, design and control of MBR systems (Ng and Kim, 2007). Although different model approaches have been proposed for modelling different membrane types within MBR technology, there is still a lack knowledge on fouling mechanisms within anaerobic environments. Classical modelling tools based on pore blocking laws and resistance-inseries theory have shown their potential for fouling modelling, but these do not consider mechanisms such biofilm development, biofilm activity or irreversible and irrecoverable fouling consolidation, among others. Furthermore, the behavior of the membrane mechanically is not incorporated, especially when gas sparging is applied due to the complex hydrodynamics created by bubbling, or where physical scouring particles such as GAC interact with the membrane.

Hence, further work is needed to fully understand the behavior of the major components responsible of membrane fouling. The proposed filtration models focus mainly on the physical mechanisms behind fouling dynamics based mainly on attachment and detachment of foulants. Even if satisfactory results have been obtained with those models, especially in short term, further effort should be made to improve their accuracy mainly by coupling with anaerobic biological models to consider the effect of anaerobic environment on suspended solids and EPS concentrations, closely related to the biochemical model. Moreover, a better understanding of the biofilm dynamics and its composition under anaerobic conditions would upgrade the filtration models predictions. 
The modelling task becomes more complex when producing an integrated model from component tasks due to the strong interactions (both phase and mechanistic). However, modelling from a plant-wide perspective is a current trend due to its potential for accurately predicting the behavior of the system improving design, diagnosis or optimization of the process. However, model complexity could increase significantly depending on the structure of the selected single models. Therefore, the challenge of integrated modeling lies in the computational cost of the integrated model, the balancing of simple models, the definition of targets, and the collection of sufficient and appropriate data model calibration and validation (Naessens et al., 2012b). Hence, there is substantial scope and work required to develop the full potential of models applied to AnMBR.

\section{Control of anaerobic membrane bioreactors}

AnMBRs must be optimized to enhance energy production and resource recovery with minimum input energy. The optimization problem is made more complexity due to the inherent complexity involved in anaerobic processes, mainly due to the microorganism diversity and their variable sensitivity to process overloads and other disturbances such as acidification (and alkalinity), inhibition and toxicant exposure, variability of inputs, water content and rheology, foaming, stirring and mixing problems, low/high $\mathrm{C} / \mathrm{N}$ ratios (i.e ammonia inhibition and lack of macro-and micro-nutrients, shifts in microbial community caused by MBR operation, and membrane fouling. In this context, efficient control strategies are important to optimize both biological and filtration operations.

Different control tools have been proposed from simple flux control to advanced control for both the anaerobic process and membrane filtration. As for anaerobic process control, in the last two decades there has been an increasing interest to develop advanced control schemes. Concerning filtration process control, considerable efforts have been made to control fouling in aerobic MBR technology. However, few control strategies have been developed and validated to optimize the performance of filtration in AnMBRs.

\subsection{Biological process control}

Over the last 50 years many different control strategies of anaerobic digestion processes have been 
reported to different substrates such as wastewater (the vast majority), agricultural substrates and organic fraction of municipal solid waste and biowaste (Gaida et al., 2017). Most of the available control strategies available within the AD field can be easily adapted for AnMBR optimization but the effect of membrane performance on the biology of the process should be taken into account.

Figure 4a summarizes some of the control strategies applied to the biological process in an AD system such as AnMBR. The most applied strategies deal with substrate feed control aimed at stabilizing the process and maximizing methane production complying with effluent criteria whenever needed (Jimenez et al., 2015). Depending on control objectives, control variables such as methane flow rate, effluent COD and VFA/Alkalinity are selected. This type of controller, ranging from classical PID controllers up to advanced control, generally use feed flow or feed dilution as manipulated variable. When more than one substrate is involved in the anaerobic process, the other substrates are calculated on the basis of boundary conditions such as organic loading rate, $\mathrm{HRT}$, and $\mathrm{C} / \mathrm{N}$ ratio among others. Other $\mathrm{AD}$ control strategies that can be found in literature are based on alkalinity and $\mathrm{pH}$ control by dosing bases (such as caustic) to stabilize the process, temperature control (Robles et al., 2015), and foaming/stirring/mixing control by modifying liquid/sludge recirculation rates (Pezzolla et al., 2017).

Mostly, feed control with alkalinity/pH/mixing control is used in a cascade configuration to achieve a performance objective (e.g. maximize methane production) and/or stability objective (e.g., pH, VFA). Concerning classical controllers, García-Diéguez et al. (2011) proposed a PID-cascade for maximizing methane production whilst maintaining a low VFA set-point, and Alvarez-Ramirez et al. (2002) aimed at maximizing COD degradation through feedback control. As for advanced controllers, a wide range of control types has been reported; rule-based, fuzzy systems, artificial neural network, model-based, and linear control among others. As an example, Holubar et al. (2003) applied a neural network aimed at maximizing methane production and COD degradation by manipulating organic loading rate (OLR) on the basis of pH, VFA, and biogas production and composition; Méndez-Acosta et al. (2010) developed a model-based multiple-input multiple-output feedback control with an extended Luenberger observer to improve the stability of anaerobic digestion processes. Regarding AnMBR, Robles et al. (2015) proposed 
OLR control by manipulating the filtration to relaxation ratio on the basis of the solids concentration in the wastewater entering the system.

\subsection{Filtration process control}

One key operating challenge of AnMBR technology is how membrane performance can be optimized whilst minimizing membrane fouling - in particular the irreversible/permanent component that cannot be eliminated by chemical cleaning and ultimately determines the membrane lifespan.

Two types of terminology are commonly used for classifying the control systems for filtration in MBR technology; either (1) related to the nature of the controlled and manipulated variables; or (2) strictly related to the nature of the controller (Ferrero et al., 2012). In the first case, the control systems for filtration in MBR technology usually involve the regulation of gas scouring, membrane operating stages, including flux, duration and frequency of the stages that comprise the operating mode (mainly filtration, relaxation, and back-flushing), and chemical cleaning (see Figure 4b). In the second case, the control systems are simply classified as open-loop or closed-loop control. In the open-loop mode, the control does not depend on the actual state of the system. For instance, depending on the practical application, membrane manufacturers may provide data on the sequence of filtration/backwash to be applied for fouling control. Thus, open-loop mode consists of simple operating strategies for fouling mitigation. It is worth pointing out that membrane scouring by gas sparging is a key control variable in both open-loop and closed-loop control systems. Hence, the main currently implemented control systems for filtration in MBR technology entail controlling gasification, permeate flux and fouling rate by manipulating gasification flow, permeate flux, permeation and relaxation duration, back-flushing duration and initiation, maintenance and recovery chemical cleaning initiation, TMP and cross-flow velocity.

Different open-loop and close-loop control systems have been developed and validated for Aerobic MBRs, even at full-scale (Vargas et al., 2008; Vera et al., 2014). Several studies published recently have theoretically analyzed and experimentally validated the energy savings of different types of advanced control (mainly model-based or knowledge-based) in aerobic MBR technology (Ferrero et al., 2012). Thus, a wide range of control strategies to optimize membrane performance have been reported in 
literature (mostly aerobic MBR), from simple operating strategies to more sophisticated advanced control systems. However, there is far less literature related to AnMBR fouling control.

\subsubsection{Open-loop control}

The most common operating strategies for open-loop control of fouling can be classified into physical cleaning (gas scouring, scouring agents, and membrane operating mode) and chemical cleaning. Hence, a suitable physical and chemical membrane cleaning protocol must be applied to given filtration conditions to ensure continuous process performance. Table 1 summarizes some physical and chemical cleaning protocols for fouling control in AnMBR.

The use of gas scouring has been widely adopted to control membrane fouling, however this physical cleaning accounts for a significant term in energy demand for MBR technology (Aslam et al., 2017a). In this respect, much effort has been focused in the last years on optimizing gas sparging intensity in AnMBR technology (Fox and Stuckey, 2015; Park et al., 2010; Robles et al., 2012a; Zhang et al., 2017a). Recently, the use of scouring agents in MBRs as a mechanical cleaning has appeared as a new energyefficient approach to fouling mitigation (Aslam et al., 2017b). Different additives such as activated carbon, polyelectrolytes, coagulants and flocculants can be used to improve the flux and to reduce fouling in AnMBRs (Aslam et al., 2014; Hu and Stuckey, 2007; Zhang et al., 2017a).

Other innovative physical cleanings are electrically assisted fouling mitigation (Ding et al., 2018) and vibration/rotation of membranes to create high shear or turbulence at the membrane surface (De Vrieze et al., 2014).

Regarding cross-flow filtration, some studies has reported physical cleaning protocols with crossflow velocity (Gao et al., 2010; Hu et al., 2017). Other methods include frequency and duration of relaxation and back-flushing (Lew et al., 2009; Robles et al., 2013a). Although higher fouling amounts are expected to be removed if increasing back-flushing duration and frequency, optimizing this operating stage is essential for minimizing energy consumption while maximizing flux through the membranes (Le-Clech et al., 2006).

It is expected that physical cleaning effectiveness will tend to decrease over time due to the 
accumulation of irreversible fouling on the membrane surface. Therefore, different chemical cleaning protocols may also be applied (J. Kim et al., 2011; Lew et al., 2009). Nevertheless, continuous application of chemical cleaning protocols is not recommended since they negatively affect membrane lifespan (Zhang et al., 2007).

\subsubsection{Closed-loop control}

Closed-loop control allows a much more robust approach at the price of a higher complexity (mainly the need for and dependence on a measurable on-line output). Jeison and van Lier (2006) developed an on-line cake-layer management protocol that monitored critical flux constantly and prevented the build-up of excessive cake layer on the membrane surface. Different authors (Kalboussi et al., 2018; Robles et al., 2013b; Vargas et al., 2008; Vera et al., 2014; Villarroel et al., 2013) proposed different on-line control strategies for backwashing initiation, while Robles et al. (2014b) optimized the frequency of backwashing through a model-based optimization algorithm.

Regarding gas-assisted membrane scouring, Park et al. (2010) studied how membrane fouling could be reduced by simultaneous upward and downward gas sparging in a pilot-scale immersed membrane bioreactor for sewage treatment. Robles et al. (2013b), demonstrated an upper layer fuzzy-logic controller to efficiently maintain low fouling rates. In addition, a model-based optimization method has also been applied to improve the performance of AnMBRs (Robles et al., 2014b). This method was effectively used for optimization of an advanced control system (consisting of an upper-layer fuzzy-logic controller), obtaining energy savings of up to $25 \%$.

Control approaches involving optimal control theory have been also proposed to maximize filtration process productivity, thus achieving a certain optimality criterion (e.g. a cost function) based on a control law for a given filtration process. Cristea et al. (2013) applied optimal control theory to optimize a microfiltration system installed in a production line of beer. The objective of the optimization was the minimization of the energy cost due to backwashing of the membrane. An optimal control problem has been defined by Paulen et al. (2015) to optimize the operation of a filtration process. The authors considered a complex goal of optimization which takes into account the minimization of the duration of 
the treatment, the reduction of the volume diluent consumed and product losses. The problem of optimization in this case is an optimal multi-objective control problem. The operating strategy optimal has been analytically determined by the application of the Principle Maximum of Pontryagin.

Similarly, the optimization objective of Jelemenský et al. (2016) was to determine the optimal operating strategy allowing the maximization of the total filtration time by limiting the clogging of the membrane. An application on a case study showed that the optimal strategy allows for significant gains in operating time and consumption of thinner in comparison with a conventional strategy of operation. Cogan et al. (2016) applied the Pontryagin Maximum principle to predict the optimal times of switching between periods of filtration and backwashing that maximize the net production of water over a running time given a membrane filtration process. The authors adopted a specific model published in the literature describing the dynamics of the ultrafiltration/microfiltration reaching promising results. This solution, however, is applicable only at very specific initial conditions, corresponding to a completely clean or new membrane. This is why such a work has been revisited recently and solved using the Pontryagin Principle together with a simple model of membrane fouling. In this way, (Kalboussi et al., 2018) stated that to maximize the quantity of matter to be filtered over a given period of time, there exists an optimal ratio between filtration and backwash time periods.

\subsection{Perspectives on process control}

Although different approaches have been proposed for controlling different variables within $A D$ technology, biological process control for AnMBRs is still at an early stage. The biological process control approach to choose in AnMBRs mainly depends on the application of the AD process and the type of substrate. Considering a general classification of substrates as low-strength WW, high-strength WW, and solid waste as a sole substrate or as a co-substrate, different control approaches are required to maximize methane production whilst maintaining process stability and effluent criteria. For low-strength WW, which are usually characterized by high influent flows (i.e. sewage), control objectives are focused on meeting effluent criteria in terms of COD and maintaining a relatively high flux. In this case, the available manipulated variables are reduced to SRT and the sludge recycling ratio (SRR), since the 
temperature control is not feasible due to the high treatment flows and HRT cannot be modified easily (Ozgun et al., 2013; Shin and Bae, 2018). Feed blending can be also enable process performance optimization whenever the low-strength WW is co-digested with other substrates such as food waste, manure or other biowastes (Pretel et al., 2016a). In contrast, the more manipulated variables are available for high-strength WW treatment or solid wastes in AnMBRs, including temperature, SRT, HRT, OLR and SRR. In this case, most of the process control strategies reported for conventional anaerobic digestion processes can be applied also to AnMBRs, taking into account that with this emerging technology both HRT and SRT can be manipulating separately, offering thus further optimization (Dereli et al., 2012). Concerning co-digestion processes, feed blending must also be considered as a manipulated variable to enhance process performance (Capson-Tojo et al., 2016).

Regarding filtration control, although different control strategies are available for optimizing filtration process performance in MBRs in general, less work has been done on the optimization of membrane systems within anaerobic environments. Apart from the already available control systems for AnMBRs (mostly dealing with the filtration process as shown in previous sections), other available control systems for optimizing MBR technology can be adapted for AnMBRs. Normally, closed-loop control allows a more robust approach at the price of a higher complexity than open-loop control. Significant advances in openloop control have been achieved in the past decades due to an increased in-depth understanding on membrane fouling (Aslam et al., 2018, 2017c; Wang et al., 2014). One major challenge is minimizing total operating downtime related to relaxation and back-flushing to make AnMBR technology economically feasible.

Generally, closed-loop control is based on feedback or model-based approaches, although knowledge-based (fuzzy logic) controllers have been applied, as noted above. The main drawback of control systems based on model-based approaches is that the complexity of the mechanisms involved makes it impossible to describe fouling exactly or build a deterministic filtration model (Ferrero et al., 2011). Due to the highly non-linear relations found throughout the physical separation processes and the large number of filtration mechanisms, the results achieved by model-based controllers are only 
acceptable when the process dynamics are bounded by a well-defined linear zone. In filtration control, most of the models used for control design are limited to the description of fouling dynamics and ignore biology of the reactor, although the actions taken to control membrane fouling have consequences on the biological dynamics. For instance, Kalboussi et al. (2018) considered constant solid concentrations in the modeling of fouling while the backwashing used for cake layer control impacted the biology of the system and thus on the solid concentration dynamics. Such feedback mechanisms should be considered to optimize the whole process.

The main challenges of application of general MBR and anaerobic process control systems to AnMBR technology includes a lack of robust and reliable online instrumentation and a limited interest for endusers and technology providers to implement these advanced control strategies (Gaida et al., 2017). The latter relates to limited demonstration of the advantages of these strategies. Advanced control strategies should enhance application and operation of full-scale AnMBRs and thus facilitate application of this important emerging technology.

\section{Conclusions}

Although the AnMBR process modelling field is relatively immature, it has strong potential to enhance improvement in the design, operation and control of these systems. It will further optimize system performance and reduce costs, and increase applicability of the technology. Membrane fouling varies greatly depending the nature of the foulant material in heterogeneous conditions. Better understanding individual and collective foulant behavior is required to better predict treatment efficiency by representing key interactions between biology and fouling dynamics. Further study is required into open and closedloop control strategies to optimize AnMBRs on an industrial scale mainly due to lack of mechanistic knowledge of fouling in AnMBRs.

\section{ACKNOWLEDGEMENTS}

This work has been carried out under the umbrella of the Task Group on Membrane Bioreactor Modelling and Control of the International Water Association (IWA) (http://www.iwa-network.org/groups/membrane-bioreactor-modelling-and-control/). The authors also want to acknowledge the support from Basic Science Research Program through the National Research 
Foundation of Korea (NRF) funded by the Ministry of Science \& ICT (2017R1A2B4007804)

\section{REFERENCES}

1. Ahmed, W., Rodríguez, J., 2018. Modelling sulfate reduction in anaerobic digestion: Complexity evaluation and parameter calibration. Water Res. 130, 255-262.

2. Aquino, S.F., Stuckey, D.C., 2008. Integrated model of the production of soluble microbial products (SMP) and extracellular polymeric substances (EPS) in anaerobic chemostats during transient conditions. Biochem. Eng. J. 38, 138-146.

3. Aslam, M., Ahmad, R., Kim, J., 2018. Recent developments in biofouling control in membrane bioreactors for domestic wastewater treatment. Sep. Purif. Technol. 206, 297-315.

4. Aslam, M., Charfi, A., Kim, J., 2017a. Membrane scouring to control fouling under fluidization of nonadsorbing media for wastewater treatment. Environ. Sci. Pollut. Res.

5. Aslam, M., Charfi, A., Lesage, G., Heran, M., Kim, J., 2017b. Membrane bioreactors for wastewater treatment: A review of mechanical cleaning by scouring agents to control membrane fouling. Chem. Eng. J. 307, 897-913.

6. Aslam, M., Kim, J., 2017. Investigating membrane fouling associated with GAC fluidization on membrane with effluent from anaerobic fluidized bed bioreactor in domestic wastewater treatment. Environ. Sci. Pollut. Res.

7. Aslam, M., McCarty, P.L., Bae, J., Kim, J., 2014. The effect of fluidized media characteristics on membrane fouling and energy consumption in anaerobic fluidized membrane bioreactors. Sep. Purif. Technol. 132, 10-15.

8. Aslam, M., McCarty, P.L., Shin, C., Bae, J., Kim, J., 2017c. Low energy single-staged anaerobic fluidized bed ceramic membrane bioreactor (AFCMBR) for wastewater treatment. Bioresour. Technol. 240, 33-41.

9. Baek, S.H., Pagilla, K.R., 2006. Aerobic and Anaerobic Membrane Bioreactors for Municipal Wastewater Treatment. Water Environ. Res. 78, 133-140. 
10. Barat, R., Serralta, J., Ruano, M.V., Jiménez, E., Ribes, J., Seco, A., Ferrer, J., 2013. Biological Nutrient Removal Model No. 2 (BNRM2): a general model for wastewater treatment plants. Water Sci. Technol. 67, 1481 LP-1489.

11. Barrera, E.L., Spanjers, H., Solon, K., Amerlinck, Y., Nopens, I., Dewulf, J., 2015. Modeling the anaerobic digestion of cane-molasses vinasse: Extension of the Anaerobic Digestion Model No. 1 (ADM1) with sulfate reduction for a very high strength and sulfate rich wastewater. Water Res. 71, 42-54.

12. Batstone, D.J., 2006. Mathematical Modelling of Anaerobic Reactors Treating Domestic Wastewater: Rational Criteria for Model Use. Rev. Environ. Sci. Bio/Technology 5, 57-71.

13. Batstone, D.J., Hülsen, T., Mehta, C.M., Keller, J., 2015a. Platforms for energy and nutrient recovery from domestic wastewater: A review. Chemosphere 140, 2-11.

14. Batstone, D.J., Keller, J., Angelidaki, I., Kalyuzhnyi, S. V, Pavlostathis, S.G., Rozzi, A., Sanders, W.T.M., Siegrist, H., Vavilin, V.A., 2002. The IWA Anaerobic Digestion Model No 1 (ADM1). Water Sci. Technol. 45, 65 LP-73.

15. Batstone, D.J., Puyol, D., Flores-alsina, X., Rodríguez, J., 2015b. Mathematical modelling of anaerobic digestion processes : applications and future needs. Rev. Environ. Sci. Bio/Technology 595-613. 4

16. Batstone, D.J., Virdis, B., 2014. The role of anaerobic digestion in the emerging energy economy. Curr. Opin. Biotechnol. 27, 142-149.

17. Becker, A.M., Yu, K., Stadler, L.B., Smith, A.L., 2017. Co-management of domestic wastewater and food waste: A life cycle comparison of alternative food waste diversion strategies. Bioresour. Technol. 223, 131140.

18. Benyahia, B., Sari, T., Cherki, B., Harmand, J., 2013. Anaerobic membrane bioreactor modeling in the presence of Soluble Microbial Products (SMP) - the Anaerobic Model AM2b. Chem. Eng. J. 228, 10111022.

19. Bernard, O., Hadj-Sadok, Z., Dochain, D., Genovesi, A., Steyer, J.P., 2001. Dynamical model development and parameter identification for an anaerobic wastewater treatment process. Biotechnol. Bioeng. 75, 424438. 
20. Böhm, L., Drews, A., Prieske, H., Bérubé, P.R., Kraume, M., 2012. The importance of fluid dynamics for MBR fouling mitigation. Bioresour. Technol. 122, 50-61.

21. Bolton, G.R., Boesch, A.W., Lazzara, M.J., 2006. The effects of flow rate on membrane capacity: Development and application of adsorptive membrane fouling models. J. Memb. Sci. 279.

22. Boyle-Gotla, A., Jensen, P.D., Yap, S.D., Pidou, M., Wang, Y., Batstone, D.J., 2014. Dynamic multidimensional modelling of submerged membrane bioreactor fouling. J. Memb. Sci. 467.

23. Capson-Tojo, G., Rouez, M., Crest, M., Steyer, J.-P., Delgenès, J.-P., Escudié, R., 2016. Food waste valorization via anaerobic processes: a review. Rev. Environ. Sci. Bio/Technology 15, 499-547.

24. Cashman, S., Ma, X., Mosley, J., Garland, J., Crone, B., Xue, X., 2018. Energy and greenhouse gas life cycle assessment and cost analysis of aerobic and anaerobic membrane bioreactor systems: Influence of scale, population density, climate, and methane recovery. Bioresour. Technol. 254, 56-66.

25. Charfi, A., Aslam, M., Kim, J., 2018a. Modelling approach to better control biofouling in fluidized bed membrane bioreactor for wastewater treatment. Chemosphere 191, 136-144.

26. Charfi, A., Aslam, M., Lesage, G., Heran, M., Kim, J., 2017a. Macroscopic approach to develop fouling model under GAC fluidization in anaerobic fluidized bed membrane bioreactor. J. Ind. Eng. Chem. 49, 219229.

27. Charfi, A., Ben Amar, N., Harmand, J., 2012. Analysis of fouling mechanisms in anaerobic membrane bioreactors. Water Res. 46, 2637-2650.

28. Charfi, A., Harmand, J., Ben Amar, N., Grasmick, A., Heran, M., 2014. Deposit membrane fouling: influence of specific cake layer resistance and tangential shear stresses. Water Sci. Technol. 70, 40.

29. Charfi, A., Park, E., Aslam, M., Kim, J., 2018b. Particle-sparged anaerobic membrane bioreactor with fluidized polyethylene terephthalate beads for domestic wastewater treatment: Modelling approach and fouling control. Bioresour. Technol. 258, 263-269.

30. Charfi, A., Thongmak, N., Benyahia, B., Aslam, M., Harmand, J., Amar, N. Ben, Lesage, G., Sridang, P., Kim, J., Heran, M., 2017b. A modelling approach to study the fouling of an anaerobic membrane bioreactor for industrial wastewater treatment. Bioresour. Technol. 245, 207-215. 
31. Charfi, A., Yang, Y., Harmand, J., Ben Amar, N., Heran, M., Grasmick, A., 2015. Soluble microbial products and suspended solids influence in membrane fouling dynamics and interest of punctual relaxation and/or backwashing. J. Memb. Sci. 475, 156-166.

32. Chellam, S., Cogan, N.G., 2011. Colloidal and bacterial fouling during constant flux microfiltration: Comparison of classical blocking laws with a unified model combining pore blocking and EPS secretion. J. Memb. Sci. 382, 148-157.

33. Chen, S., Smith, A.L., 2018. Methane-driven microbial fuel cells recover energy and mitigate dissolved methane emissions from anaerobic effluents. Environ. Sci. Water Res. Technol. 4, 67-79.

34. Choo, K.-H., Lee, C.-H., 1998. Hydrodynamic behavior of anaerobic biosolids during crossflow filtration in the membrane anaerobic bioreactor. Water Res. 32, 3387-3397.

35. Cogan, N.G., Li, J., Badireddy, A.R., Chellam, S., 2016. Optimal backwashing in dead-end bacterial microfiltration with irreversible attachment mediated by extracellular polymeric substances production. J. Memb. Sci. 520, 337-344.

36. Cookney, J., Mcleod, A., Mathioudakis, V., Ncube, P., Soares, A., Jefferson, B., McAdam, E.J., 2016. Dissolved methane recovery from anaerobic effluents using hollow fibre membrane contactors. J. Memb. Sci. 502, 141-150.

37. Cordell, D., White, S., 2013. Sustainable Phosphorus Measures: Strategies and Technologies for Achieving Phosphorus Security. Agronomy 3, 86-116.

38. Cristea, S.P., Mazaeda, R., de Prada, C., 2013. Optimal Control of Beer Filtration Process. IFAC Proc. Vol. $46,762-767$.

39. Crone, B.C., Garland, J.L., Sorial, G.A., Vane, L.M., 2016. Signi fi cance of dissolved methane in ef fl uents of anaerobically treated low strength wastewater and potential for recovery as an energy product : A review. Water Res. 104, 520-531.

40. Cui, Z.., Chang, S., Fane, A.., 2003. The use of gas bubbling to enhance membrane processes. J. Memb. Sci. 221, 1-35. 
41. De Bruijn, J.P.F., Salazar, F.N., Bórquez, R., 2005. Membrane Blocking In Ultrafiltration: A New Approach to Fouling. Food Bioprod. Process. 83, 211-219.

42. De Vrieze, J., Hennebel, T., Van den Brande, J., Bilad, R.M., Bruton, T.A., Vankelecom, I.F.J., Verstraete, W., Boon, N., 2014. Anaerobic digestion of molasses by means of a vibrating and non-vibrating submerged anaerobic membrane bioreactor. Biomass and Bioenergy 68, 95-105.

43. Dereli, R.K., Ersahin, M.E., Ozgun, H., Ozturk, I., Jeison, D., van der Zee, F., van Lier, J.B., 2012. Potentials of anaerobic membrane bioreactors to overcome treatment limitations induced by industrial wastewaters. Bioresour. Technol. 122, 160-170.

44. Ding, A., Fan, Q., Cheng, R., Sun, G., Zhang, M., Wu, D., 2018. Impacts of applied voltage on microbial electrolysis cell-anaerobic membrane bioreactor (MEC-AnMBR) and its membrane fouling mitigation mechanism. Chem. Eng. J. 333, 630-635.

45. Do Nascimento, M., Sanchez Rizza, L., Arruebarrena Di Palma, A., Dublan, M. de los A., Salerno, G., Rubio, L.M., Curatti, L., 2015. Cyanobacterial biological nitrogen fixation as a sustainable nitrogen fertilizer for the production of microalgal oil. Algal Res. 12, 142-148.

46. Donoso-bravo, A., Mailier, J., Martin, C., Rodrı, J., Aceves-lara, A., Vande, A., 2011. Model selection, identification and validation in anaerobic digestion : A review 5.

47. Drews, A., Arellano-Garcia, H., Schöneberger, J., Schaller, J., Wozny, G., Kraume, M., 2009. Model-based recognition of fouling mechanisms in membrane bioreactors. Desalination 236, 224-233.

48. Durán, F., 2013. Mathematical modelling of the anaerobic urban wastewater treatment including sulphatereducing bacteria. Application to an anaerobic membrane bioreactor (Modelación matemática del tratamiento anaerobio de aguas residuales urbanas incluyendo las bacterias . Universitat Politècnica de València.

49. Durán, F., Robles, A., Seco, A., Ferrer, J., Ribes, J., Serralta, J., 2017. Modelling the anaerobic treatment of urban wastewater: application to AnMBR technology, in: 15th IWA World Conference on Anaerobic Digestion (AD15). Beijing. 
50. Durán, F., Zamorano-López, N., Barat, R., Ferrer, J., Aguado, D., 2018. Understanding the performance of an AnMBR treating urban wastewater and food waste via model simulation and characterization of the microbial population dynamics. Process Biochem. 67, 139-146.

51. Fedorovich, V., Lens, P., Kalyuzhnyi, S., 2003. Extension of Anaerobic Digestion Model No. 1 with Processes of Sulfate Reduction. Appl. Biochem. Biotechnol. 109, 33-46.

52. Ferrer, J., Pretel, R., Durán, F., Giménez, J.B., Robles, A., Ruano, M. V., Serralta, J., Ribes, J., Seco, A., 2015. Design methodology for submerged anaerobic membrane bioreactors (AnMBR): A case study. Sep. Purif. Technol. 141, 378-386.

53. Ferrero, G., Monclús, H., Buttiglieri, G., Comas, J., Rodriguez-Roda, I., 2011. Automatic control system for energy optimization in membrane bioreactors. Desalination 268, 276-280.

54. Ferrero, G., Rodríguez-Roda, I., Comas, J., 2012. Automatic control systems for submerged membrane bioreactors: A state-of-the-art review. Water Res. 46, 3421-3433.

55. Field, R.W., Wu, D., Howell, J.A., Gupta, B.B., 1995. Critical flux concept for microfiltration fouling. J. Memb. Sci. 100, 259-272.

56. Fomichev, A.O., Vavilin, V.A., 1997. The reduced model of self-oscillating dynamics in an anaerobic system with sulfate-reduction. Ecol. Modell. 95, 133-144. 5

57. Fox, R.A., Stuckey, D.C., 2015. The effect of sparging rate on transmembrane pressure and critical flux in an AnMBR. J. Environ. Manage. 151, 280-285.

58. Frunzo, L., Esposito, G., Pirozzi, F., Lens, P., 2012. Dynamic mathematical modeling of sulfate reducing gas-lift reactors. Process Biochem. 47, 2172-2181.

59. Gaida, D., Wolf, C., Bongards, M., 2017. Feed control of anaerobic digestion processes for renewable energy production: A review. Renew. Sustain. Energy Rev. 68, 869-875.

60. Galib, M., Elbeshbishy, E., Reid, R., Hussain, A., Lee, H.S., 2016. Energy-positive food wastewater treatment using an anaerobic membrane bioreactor (AnMBR). J. Environ. Manage. 182, 477-485. 
61. Gao, D.-W., Zhang, T., Tang, C.-Y.Y., Wu, W.-M., Wong, C.-Y., Lee, Y.H., Yeh, D.H., Criddle, C.S., 2010. Membrane fouling in an anaerobic membrane bioreactor: Differences in relative abundance of bacterial species in the membrane foulant layer and in suspension. J. Memb. Sci. 364, 331-338.

62. García-Diéguez, C., Molina, F., Roca, E., 2011. Multi-objective cascade controller for an anaerobic digester. Process Biochem. 46, 900-909.

63. Giménez, J.B., Robles, A., Carretero, L., Durán, F., Ruano, M. V., Gatti, M.N., Ribes, J., Ferrer, J., Seco, A., 2011. Experimental study of the anaerobic urban wastewater treatment in a submerged hollow-fibre membrane bioreactor at pilot scale. Bioresour. Technol. 102, 8799-8806.

64. Hao, X., Batstone, D.J., Guest, J.S., 2015. Carbon neutrality: An ultimate goal towards sustainable wastewater treatment plants. Water Res. 87, 413-415.

65. Harerimana, C., Keffala, C., Jupsin, H., Vasel, J.-L., 2013. Development of a simple model for anaerobic digestion based on preliminary measurements of the bacterial sulphur activity in wastewater stabilization ponds. Environ. Technol. 34, 2213-2220.

66. Henares, M., Izquierdo, M., Marzal, P., Martínez-Soria, V., 2017. Demethanization of aqueous anaerobic effluents using a polydimethylsiloxane membrane module: Mass transfer, fouling and energy analysis. Sep. Purif. Technol. 186, 10-19.

67. Henares, M., Izquierdo, M., Penya-Roja, J.M., Martínez-Soria, V., 2016. Comparative study of degassing membrane modules for the removal of methane from Expanded Granular Sludge Bed anaerobic reactor effluent. Sep. Purif. Technol. 170, 22-29.

68. Holubar, P., Zani, L., Hager, M., Fröschl, W., Radak, Z., Braun, R., 2003. Start-up and recovery of a biogas-reactor using a hierarchical neural network-based control tool. J. Chem. Technol. Biotechnol. 78, 847-854.

69. Hu, A.Y., Stuckey, D.C., 2007. Activated Carbon Addition to a Submerged Anaerobic Membrane Bioreactor: Effect on Performance, Transmembrane Pressure, and Flux. J. Environ. Eng. 133, 73-80. 
70. Hu, D., Xiao, T., Chen, Z., Wang, H., Xu, J., Li, X., Su, H., Zhang, Y., 2017. Effect of the high cross flow velocity on performance of a pilot-scale anaerobic membrane bioreactor for treating antibiotic solvent wastewater. Bioresour. Technol. 243, 47-56.

71. Huang, X., Wei, C.-H., Yu, K.-C., 2008. Mechanism of membrane fouling control by suspended carriers in a submerged membrane bioreactor. J. Memb. Sci. 309, 7-16.

72. Huang, Z., Ong, S.L., Ng, H.Y., 2011. Submerged anaerobic membrane bioreactor for low-strength wastewater treatment: Effect of HRT and SRT on treatment performance and membrane fouling. Water Res. 45, 705-713.

73. Iritani, E., Katagiri, N., 2016. Developments of Blocking Filtration Model in Membrane Filtration. KONA Powder Part. J. 33, 179-202.

74. Jeison, D., Telkamp, P., van Lier, J.B., 2009. Thermophilic Sidestream Anaerobic Membrane Bioreactors: The Shear Rate Dilemma. Water Environ. Res. 81, 2372-2380.

75. Jeison, D., van Lier, J.B., 2006. On-line cake-layer management by trans-membrane pressure steady state assessment in Anaerobic Membrane Bioreactors for wastewater treatment. Biochem. Eng. J. 29, 204-209.

76. Jelemenský, M., Sharma, A., Paulen, R., Fikar, M., 2016. Time-optimal control of diafiltration processes in the presence of membrane fouling. Comput. Chem. Eng. 91, 343-351.

77. Jimenez, J., Latrille, E., Harmand, J., Robles, A., Ferrer, J., Gaida, D., Wolf, C., Mairet, F., Bernard, O., Alcaraz-Gonzalez, V., Mendez-Acosta, H., Zitomer, D., Totzke, D., Spanjers, H., Jacobi, F., Guwy, A., Dinsdale, R., Premier, G., Mazhegrane, S., Ruiz-Filippi, G., Seco, A., Ribeiro, T., Pauss, A., Steyer, J.-P., 2015. Instrumentation and control of anaerobic digestion processes: a review and some research challenges. Rev. Environ. Sci. Bio/Technology 14, 615-648.

78. Kalboussi, N., Harmand, J., Rapaport, A., Bayen, T., Ellouze, F., Ben Amar, N., 2018. Optimal control of physical backwash strategy - towards the enhancement of membrane filtration process performance. J. Memb. Sci. 545, 38-48. 
79. Kalyuzhnyi, S., Fedorovich, V., Lens, P., Hulshoff Pol, L., Lettinga, G., 1998. Mathematical modelling as a tool to study population dynamics between sulfate reducing and methanogenic bacteria. Biodegradation 9, 187-199.

80. Kamali, M., Khodaparast, Z., 2015. Review on recent developments on pulp and paper mill wastewater treatment. Ecotoxicol. Environ. Saf. 114, 326-342.

81. Katsoufidou, K., Yiantsios, S.G., Karabelas, A.J., 2005. A study of ultrafiltration membrane fouling by humic acids and flux recovery by backwashing: Experiments and modeling. J. Memb. Sci. 266, 40-50.

82. Khan, M.A., Ngo, H.H., Guo, W.S., Liu, Y.W., Zhou, J.L., Zhang, J., Liang, S., Ni, B.J., Zhang, X.B., Wang, J., 2016. Comparing the value of bioproducts from different stages of anaerobic membrane bioreactors. Bioresour. Technol. 214, 816-825.

83. Kim, J., Kim, K., Ye, H., Lee, E., Shin, C., McCarty, P.L., Bae, J., 2011. Anaerobic Fluidized Bed Membrane Bioreactor for Wastewater Treatment. Environ. Sci. Technol. 45, 576-581.

84. Kim, M.J., Sankararao, B., Yoo, C.K., 2011. Determination of MBR fouling and chemical cleaning interval using statistical methods applied on dynamic index data. J. Memb. Sci. 375, 345-353.

85. Knobel, A.N., Lewis, A.E., 2002. A mathematical model of a high sulphate wastewater anaerobic treatment system. Water Res. 36, 257-265.

86. Le-Clech, P., Chen, V., Fane, T.A.G., 2006. Fouling in membrane bioreactors used in wastewater treatment. J. Memb. Sci. 284, 17-53.

87. Lee, M., Keller, A.A., Chiang, P.C., Den, W., Wang, H., Hou, C.H., Wu, J., Wang, X., Yan, J., 2017. Waterenergy nexus for urban water systems: A comparative review on energy intensity and environmental impacts in relation to global water risks. Appl. Energy 205, 589-601.

88. Lew, B., Tarre, S., Beliavski, M., Dosoretz, C., Green, M., 2009. Anaerobic membrane bioreactor (AnMBR) for domestic wastewater treatment. Desalination 243, 251-257.

89. Li, X., Wang, X., 2006. Modelling of membrane fouling in a submerged membrane bioreactor. J. Memb. Sci. 278, 151-161. 
90. Lin, H., Liao, B.-Q., Chen, J., Gao, W., Wang, L., Wang, F., Lu, X., 2011. New insights into membrane fouling in a submerged anaerobic membrane bioreactor based on characterization of cake sludge and bulk sludge. Bioresour. Technol. 102, 2373-2379.

91. Lin, H., Peng, W., Zhang, M., Chen, J., Hong, H., Zhang, Y., 2013. A review on anaerobic membrane bioreactors: Applications, membrane fouling and future perspectives. Desalination 314, 169-188.

92. Longo, S., d'Antoni, B.M., Bongards, M., Chaparro, A., Cronrath, A., Fatone, F., Lema, J.M., MauricioIglesias, M., Soares, A., Hospido, A., 2016. Monitoring and diagnosis of energy consumption in wastewater treatment plants. A state of the art and proposals for improvement. Appl. Energy 179, 1251-1268. d

93. Mahmoud, I., Liao, B., 2017. Effects of sludge concentration and biogas sparging rate on critical flux in a submerged anaerobic membrane bioreactor. J. Water Process Eng. 20, 51-60.

94. Mannina, G., Ekama, G., Caniani, D., Cosenza, A., Esposito, G., Gori, R., Garrido-Baserba, M., Rosso, D., Olsson, G., 2016. Greenhouse gases from wastewater treatment - A review of modelling tools. Sci. Total Environ. 551-552, 254-270. d

95. McCarty, P.L., Bae, J., Kim, J., 2011. Domestic Wastewater Treatment as a Net Energy Producer-Can This be Achieved? Environ. Sci. Technol. 45, 7100-7106.

96. Méndez-Acosta, H.O., Palacios-Ruiz, B., Alcaraz-González, V., González-Álvarez, V., García-Sandoval, J.P., 2010. A robust control scheme to improve the stability of anaerobic digestion processes. J. Process Control 20, 375-383.

97. Muñoz Sierra, J.D., Oosterkamp, M.J., Wang, W., Spanjers, H., van Lier, J.B., 2018. Impact of long-term salinity exposure in anaerobic membrane bioreactors treating phenolic wastewater: Performance robustness and endured microbial community. Water Res. 141, 172-184.

98. Naessens, W., Maere, T., Ratkovich, N., Vedantam, S., Nopens, I., 2012. Critical review of membrane bioreactor models - Part 2: Hydrodynamic and integrated models. Bioresour. Technol. 122, 107-118.

99. Nelson, M.J., Nakhla, G., Zhu, J., 2017. Fluidized-Bed Bioreactor Applications for Biological Wastewater Treatment: A Review of Research and Developments. Engineering 3, 330-342. 
100. Ng, K.K., Shi, X., Ng, H.Y., 2015. Evaluation of system performance and microbial communities of abioaugmented anaerobic membrane bioreactor treating pharmaceutical wastewater. Water Res. 81, 311324.

101. Ognier, S., Wisniewski, C., Grasmick, A., 2004. Membrane bioreactor fouling in sub-critical filtration conditions: a local critical flux concept. J. Memb. Sci. 229, 171-177.

102. Ozgun, H., Dereli, R.K., Ersahin, M.E., Kinaci, C., Spanjers, H., Van Lier, J.B., 2013. A review of anaerobic membrane bioreactors for municipal wastewater treatment: Integration options, limitations and expectations. Sep. Purif. Technol. 118, 89-104.

103. Padmasiri, S.I., Zhang, J., Fitch, M., Norddahl, B., Morgenroth, E., Raskin, L., 2007. Methanogenic population dynamics and performance of an anaerobic membrane bioreactor (AnMBR) treating swine manure under high shear conditions. Water Res. 41, 134-144.

104. Park, H.-D., Lee, Y.H., Kim, H.-B., Moon, J., Ahn, C.-H., Kim, K.-T., Kang, M.-S., 2010. Reduction of membrane fouling by simultaneous upward and downward air sparging in a pilot-scale submerged membrane bioreactor treating municipal wastewater. Desalination 251, 75-82.

105. Paulen, R., Jelemenský, M., Kovács, Z., Fikar, M., 2015. Economically optimal batch diafiltration via analytical multi-objective optimal control. J. Process Control 28, 73-82.

106. Pelaz, L., Gómez, A., Garralón, G., Letona, A., Fdz-Polanco, M., 2018. Recirculation of gas emissions to achieve advanced denitrification of the effluent from the anaerobic treatment of domestic wastewater. Bioresour. Technol. 250, 758-763.

107. Pezzolla, D., Di Maria, F., Zadra, C., Massaccesi, L., Sordi, A., Gigliotti, G., 2017. Optimization of solidstate anaerobic digestion through the percolate recirculation. Biomass and Bioenergy 96, 112-118.

108. Pileggi, V., Parker, W.J., 2017. AnMBR digestion of mixed WRRF sludges: Impact of digester loading and temperature. J. Water Process Eng. 19, 74-80. 1

109. Pretel, R., Durán, F., Robles, A., Ruano, M.V., Ribes, J., Serralta, J., Ferrer, J., 2015a. Designing an AnMBR-based WWTP for energy recovery from urban wastewater: The role of primary settling and anaerobic digestion. Sep. Purif. Technol. 156, 132-139. 
110. Pretel, R., Moñino, P., Robles, A., Ruano, M. V., Seco, A., Ferrer, J., 2016a. Economic and environmental sustainability of an AnMBR treating urban wastewater and organic fraction of municipal solid waste. J. Environ. Manage. 179, 83-92.

111. Pretel, R., Robles, A., Ruano, M.V., Seco, A., Ferrer, J., 2016b. Economic and environmental sustainability of submerged anaerobic MBR-based (AnMBR-based) technology as compared to aerobic-based technologies for moderate-/high-loaded urban wastewater treatment. J. Environ. Manage. 166, 45-54.

112. Pretel, R., Robles, A., Ruano, M.V., Seco, A., Ferrer, J., 2016c. A plant-wide energy model for wastewater treatment plants: application to anaerobic membrane bioreactor technology. Environ. Technol. 37, 22982315.

113. Pretel, R., Shoener, B.D., Ferrer, J., Guest, J.S., 2015b. Navigating environmental, economic, and technological trade-offs in the design and operation of submerged anaerobic membrane bioreactors (AnMBRs). Water Res. 87, 531-541.

114. Puyol, D., Batstone, D.J., Hülsen, T., Astals, S., Peces, M., Krömer, J.O., 2017. Resource recovery from wastewater by biological technologies: Opportunities, challenges, and prospects. Front. Microbiol. 7, 1-23.

115. Robles, A., Durán, F., Ruano, M.V., Ribes, J., Rosado, A., Seco, A., Ferrer, J., 2015. Instrumentation, control, and automation for submerged anaerobic membrane bioreactors. Environ. Technol. 36, 17951806.

116. Robles, A., Ruano, M.V., García-Usach, F., Ferrer, J., 2012a. Sub-critical filtration conditions of commercial hollow-fibre membranes in a submerged anaerobic MBR (HF-SAnMBR) system: The effect of gas sparging intensity. Bioresour. Technol. 114, 247-254.

117. Robles, A., Ruano, M.V., Ribes, J., Ferrer, J., 2013a. Factors that affect the permeability of commercial hollow-fibre membranes in a submerged anaerobic MBR (HF-SAnMBR) system. Water Res. 47, 12771288.

118. Robles, A., Ruano, M.V., Ribes, J., Ferrer, J., 2013b. Performance of industrial scale hollow-fibre membranes in a submerged anaerobic MBR (HF-SAnMBR) system at mesophilic and psychrophilic conditions. Sep. Purif. Technol. 104, 290-296. 
119. Robles, A., Ruano, M.V., Ribes, J., Ferrer, J., 2013c. Advanced control system for optimal filtration in submerged anaerobic MBRs (SAnMBRs). J. Memb. Sci. 430, 330-341.

120. Robles, A., Ruano, M.V., Ribes, J., Ferrer, J., 2012b. Sub-critical long-term operation of industrial scale hollow-fibre membranes in a submerged anaerobic MBR (HF-SAnMBR) system. Sep. Purif. Technol. 100, 88-96.

121. Robles, A., Ruano, M.V., Ribes, J., Seco, A., Ferrer, J., 2014a. Global sensitivity analysis of a filtration model for submerged anaerobic membrane bioreactors (AnMBR). Bioresour. Technol. 158, 365-373.

122. Robles, A., Ruano, M.V., Ribes, J., Seco, A., Ferrer, J., 2014b. Model-based automatic tuning of a filtration control system for submerged anaerobic membrane bioreactors (AnMBR). J. Memb. Sci. 465, 14-26.

123. Robles, A., Ruano, M.V., Ribes, J., Seco, A., Ferrer, J., 2013d. A filtration model applied to submerged anaerobic MBRs (SAnMBRs). J. Memb. Sci. 444, 139-147.

124. Robles, A., Ruano, M.V., Ribes, J., Seco, A., Ferrer, J., 2013e. Mathematical modelling of filtration in submerged anaerobic MBRs (SAnMBRs): Long-term validation. J. Memb. Sci. 446, 303-309.

125. Sánchez-Ramírez, J.E., Seco, A., Ferrer, J., Bouzas, A., García-Usach, F., 2015. Treatment of a submerged anaerobic membrane bioreactor (SAnMBR) effluent by an activated sludge system: The role of sulphide and thiosulphate in the process. J. Environ. Manage. 147, 213-218.

126. Seib, M.D., Berg, K.J., Zitomer, D.H., 2016. Influent wastewater microbiota and temperature influence anaerobic membrane bioreactor microbial community. Bioresour. Technol. 216, 446-452.

127. Sgroi, M., Vagliasindi, F.G.A., Roccaro, P., 2018. Feasibility, sustainability and circular economy concepts in water reuse. Curr. Opin. Environ. Sci. Heal. 2, 20-25.

128. Shi, X., Leong, K.Y., Ng, H.Y., 2017. Anaerobic treatment of pharmaceutical wastewater: A critical review. Bioresour. Technol. 245, 1238-1244.

129. Shin, C., Bae, J., 2018. Current status of the pilot-scale anaerobic membrane bioreactor treatments of domestic wastewaters: A critical review. Bioresour. Technol. 247, 1038-1046.

130. Skouteris, G., Hermosilla, D., López, P., Negro, C., Blanco, Á., 2012. Anaerobic membrane bioreactors for wastewater treatment: A review. Chem. Eng. J. 198-199, 138-148. 
131. Smith, A.L., Stadler, L.B., Cao, L., Love, N.G., Raskin, L., Skerlos, S.J., 2014. Navigating wastewater energy recovery strategies: A life cycle comparison of anaerobic membrane bioreactor and conventional treatment systems with anaerobic digestion. Environ. Sci. Technol. 48.

132. Smith, A.L., Stadler, L.B., Love, N.G., Skerlos, S.J., Raskin, L., 2012. Perspectives on anaerobic membrane bioreactor treatment of domestic wastewater: A critical review. Bioresour. Technol. 122, 149159.

133. Stazi, V., Tomei, M.C., 2018. Enhancing anaerobic treatment of domestic wastewater: State of the art, innovative technologies and future perspectives. Sci. Total Environ. 635, 78-91.

134. Stuckey, D.C., 2012. Recent developments in anaerobic membrane reactors. Bioresour. Technol. 122, $137-148$.

135. Trad, Z., Vial, C., Fontaine, J.P., Larroche, C., 2015. Modeling of hydrodynamics and mixing in a submerged membrane bioreactor. Chem. Eng. J. 282, 77-90.

136. Vargas, A., Moreno-Andrade, I., Buitrón, G., 2008. Controlled backwashing in a membrane sequencing batch reactor used for toxic wastewater treatment. J. Memb. Sci. 320, 185-190.

137. Vera, L., González, E., Díaz, O., Delgado, S., 2014. Application of a backwashing strategy based on transmembrane pressure set-point in a tertiary submerged membrane bioreactor. J. Memb. Sci. 470, 504512.

138. Wang, Z., Ma, J., Tang, C.Y., Kimura, K., Wang, Q., Han, X., 2014. Membrane cleaning in membrane bioreactors: A review. J. Memb. Sci. 468, 276-307. 0

139. Wibisono, Y., Cornelissen, E.R., Kemperman, A.J.B., van der Meer, W.G.J., Nijmeijer, K., 2014. Two-phase flow in membrane processes: A technology with a future. J. Memb. Sci. 453, 566-602.

140. Wu, B., 2013. Advances in the use of CFD to characterize, design and optimize bioenergy systems. Comput. Electron. Agric. 93, 195-208.

141. Wu, J., He, C., Jiang, X., Zhang, M., 2011. Modeling of the submerged membrane bioreactor fouling by the combined pore constriction, pore blockage and cake formation mechanisms. Desalination 279, 127-134. 
142. Wu, Y., Wang, X., Tay, M.Q.X., Oh, S., Yang, L., Tang, C., Cao, B., 2017. Metagenomic insights into the influence of salinity and cytostatic drugs on the composition and functional genes of microbial community in forward osmosis anaerobic membrane bioreactors. Chem. Eng. J. 326, 462-469.

143. Zaher, U., Grau, P., Benedetti, L., Ayesa, E., Vanrolleghem, P.A., 2007a. Transformers for interfacing anaerobic digestion models to pre- and post-treatment processes in a plant-wide modelling context. Environ. Model. Softw. 22, 40-58.

144. Zaher, U., Grau, P., Benedetti, L., Ayesa, E., Vanrolleghem, P.A., 2007b. Transformers for interfacing anaerobic digestion models to pre- and post-treatment processes in a plant-wide modelling context. Environ. Model. Softw. 22, 40-58.

145. Zamorano-López, N., Moñino, P., Borrás, L., Aguado, D., Barat, R., Ferrer, J., Seco, A., 2018. Influence of food waste addition over microbial communities in an Anaerobic Membrane Bioreactor plant treating urban wastewater. J. Environ. Manage. 217, 788-796.

146. Zhang, J., Padmasiri, S.I., Fitch, M., Norddahl, B., Raskin, L., Morgenroth, E., 2007. Influence of cleaning frequency and membrane history on fouling in an anaerobic membrane bioreactor. Desalination 207, 153166.

147. Zhang, Q., (Victor) Tan, G.H., Stuckey, D.C., 2017a. Optimal biogas sparging strategy, and the correlation between sludge and fouling layer properties in a submerged anaerobic membrane bioreactor (SAnMBR). Chem. Eng. J. 319, 248-257.

148. Zhang, Q., Singh, S., Stuckey, D.C., 2017b. Fouling reduction using adsorbents/flocculants in a submerged anaerobic membrane bioreactor. Bioresour. Technol. 239, 226-235.

149. Zheng, Y., Zhang, W., Tang, B., Ding, J., Zheng, Y., Zhang, Z., 2018. Membrane fouling mechanism of biofilm-membrane bioreactor (BF-MBR): Pore blocking model and membrane cleaning. Bioresour. Technol. $250,398-405$.

150. Zuthi, M.F.R., Ngo, H.H., Guo, W.S., 2012. Modelling bioprocesses and membrane fouling in membrane bioreactor (MBR): A review towards finding an integrated model framework. Bioresour. Technol. 122, 119129. 
Table 1. Some fouling control protocols in AnMBR. Nomenclature: FS: flat-sheet; GAC: granular activated carbon; HF: hollowfiber; PAC: powdered activated carbon; PE: Polyethylene; PVDF: polyvinylidene fluoride; PTFE: polytetrafluoroethylene; PES: polyethersulfone; and

\begin{tabular}{|c|c|c|c|}
\hline $\begin{array}{l}\text { Bioreactor } \\
\text { Configuration }\end{array}$ & Membrane information & Fouling control & Reference \\
\hline $\begin{array}{l}\text { Completely mixed } \\
\text { anaerobic reactor }\end{array}$ & $0.1 \mu \mathrm{m}$ PVDF cross flow tubular & $\begin{array}{l}\text { Cross-flow; weekly cleaning with } 0.1 \% \text { w/w } \\
\mathrm{NaOH} \text { and disinfectant }\end{array}$ & Baek and Pagilla, 2006 \\
\hline AnMBR & Cross-flow micro filtration & Critical flux & $\begin{array}{l}\text { Jeison and van Lier, } \\
2006\end{array}$ \\
\hline Immersed AnMBR & $0.4 \mu \mathrm{m}$ FS & PAC/GAC+biogas sparging & Hu and Stuckey, 2007 \\
\hline $\begin{array}{l}\text { Completely mixed } \\
\text { anaerobic reactor }\end{array}$ & $0.2 \mu \mathrm{m}$ cross flow HF & $\begin{array}{l}\text { Periodic back-flushing; chemical cleaning with } \\
0.1 \mathrm{M} \mathrm{NaOH}, 1 \% \mathrm{H}_{2} \mathrm{O}_{2} \text { and } 1 \% \mathrm{HCl} \text {; and } \\
\text { periodic back-flushing }\end{array}$ & Lew et al., 2009 \\
\hline $\begin{array}{l}\text { Up-flow anaerobic } \\
\text { reactor }\end{array}$ & $\begin{array}{l}100 \mathrm{kDa} \text { cross flow coated PVDF } \\
\text { and } 30 \mathrm{kDa} \text { cross flow } \\
\text { polyetherimine }\end{array}$ & Cross-flow velocity & Gao et al., 2010 \\
\hline Immersed AnMBR & $0.07 \mu \mathrm{m}$ PVDF immersed HF & Biogas sparging & Park et al., 2010 \\
\hline $\begin{array}{l}\text { Completely mixed } \\
\text { anaerobic reactor }\end{array}$ & $0.1 \mu \mathrm{m}$ PES immersed FS & Biogas sparging & Huang et al., 2011 \\
\hline $\begin{array}{l}\text { Two-stage fluidised } \\
\text { bed MBR }\end{array}$ & $0.1 \mu \mathrm{m}$ PVDF immersed HF & $\begin{array}{l}\text { GAC fluidisation; periodic back-flushing and/or } \\
\mathrm{NaOCI} / \mathrm{NaOH} \text { cleaning }\end{array}$ & Kim et al., 2011 \\
\hline Immersed AnMBR & $0.03 \mu \mathrm{m} \mathrm{HF}$ & Critical flux & Robles et al., 2012b \\
\hline Immersed AnMBR & $0.03 \mu \mathrm{m} \mathrm{HF}$ & Backwash/biogas sparging/Relaxation & Robles et al., 2013a \\
\hline AFMBR & $0.4 \mu \mathrm{m}$ PVC FS & GAC & Aslam et al., 2014 \\
\hline Immersed AnMBR & $0.4 \mu \mathrm{m} \mathrm{FS}$ & Biogas sparging/Critical flux & Fox and Stuckey, 2015 \\
\hline AnMBR & 20-PVDF HF & Cross-flow velocity & Hu et al., 2017 \\
\hline Immersed AnMBR & $0.45 \mu \mathrm{m}$ FS & Alternate biogas sparging & Zhang et al., 2017a \\
\hline Immersed AnMBR & $0.4 \mu \mathrm{m} \mathrm{FS}$ & Various adsorbents/foulants & Zhang et al., 2017b \\
\hline UASB-AnMBR & $0.3 \mu \mathrm{m}$ PVDF immersed FS & Critical flux & $\begin{array}{l}\text { Mahmoud and Liao, } \\
2017\end{array}$ \\
\hline AFMBR & $0.5 \mu \mathrm{m}$ Flat-tubular & $\begin{array}{l}\text { Silica/Fluidized polyethylene terephthalate } \\
\text { beads }\end{array}$ & Charfi et al., 2018c \\
\hline $\begin{array}{l}\text { Microbial electrolysis } \\
\text { cell +AnMBR }\end{array}$ & $0.01 \mu \mathrm{m}$ PVDF immersed HF & Electric field by microbial electrolysis cell & Ding et al., 2018 \\
\hline
\end{tabular}



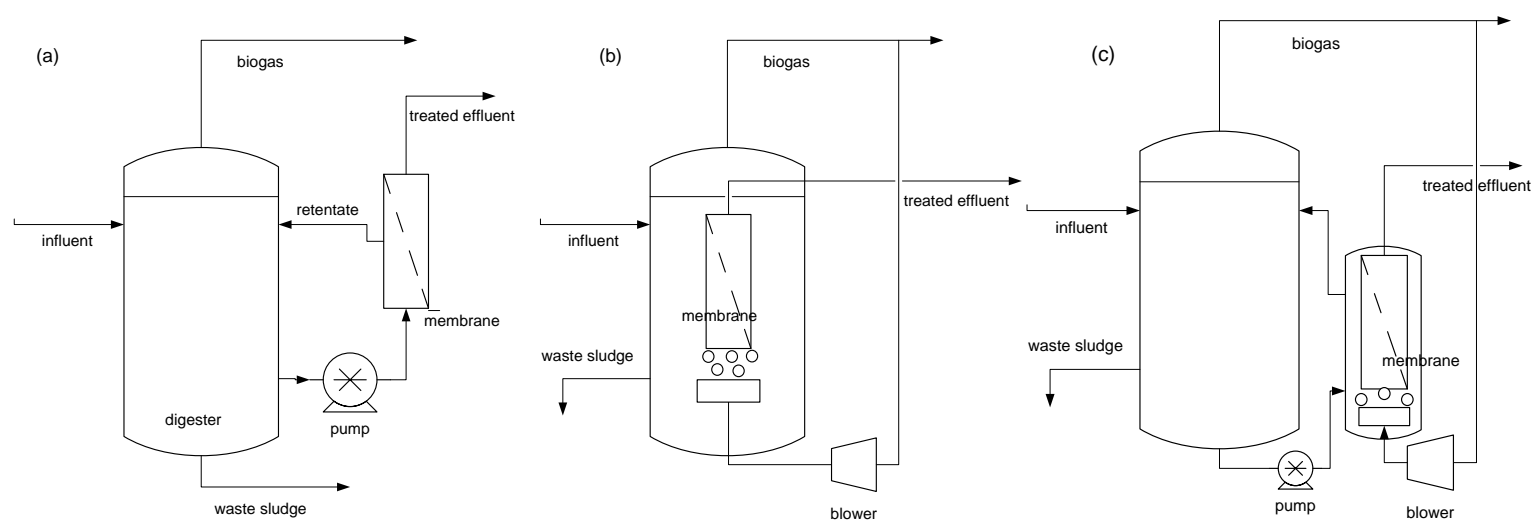

Figure 1. AnMBR configurations, including (a) Sidestream membrane bioreactor (AnSMBR) and (b) Immersed membrane bioreactor (AniMBR), and (c) the combination of sidestream approach and immersed AnMBR. 


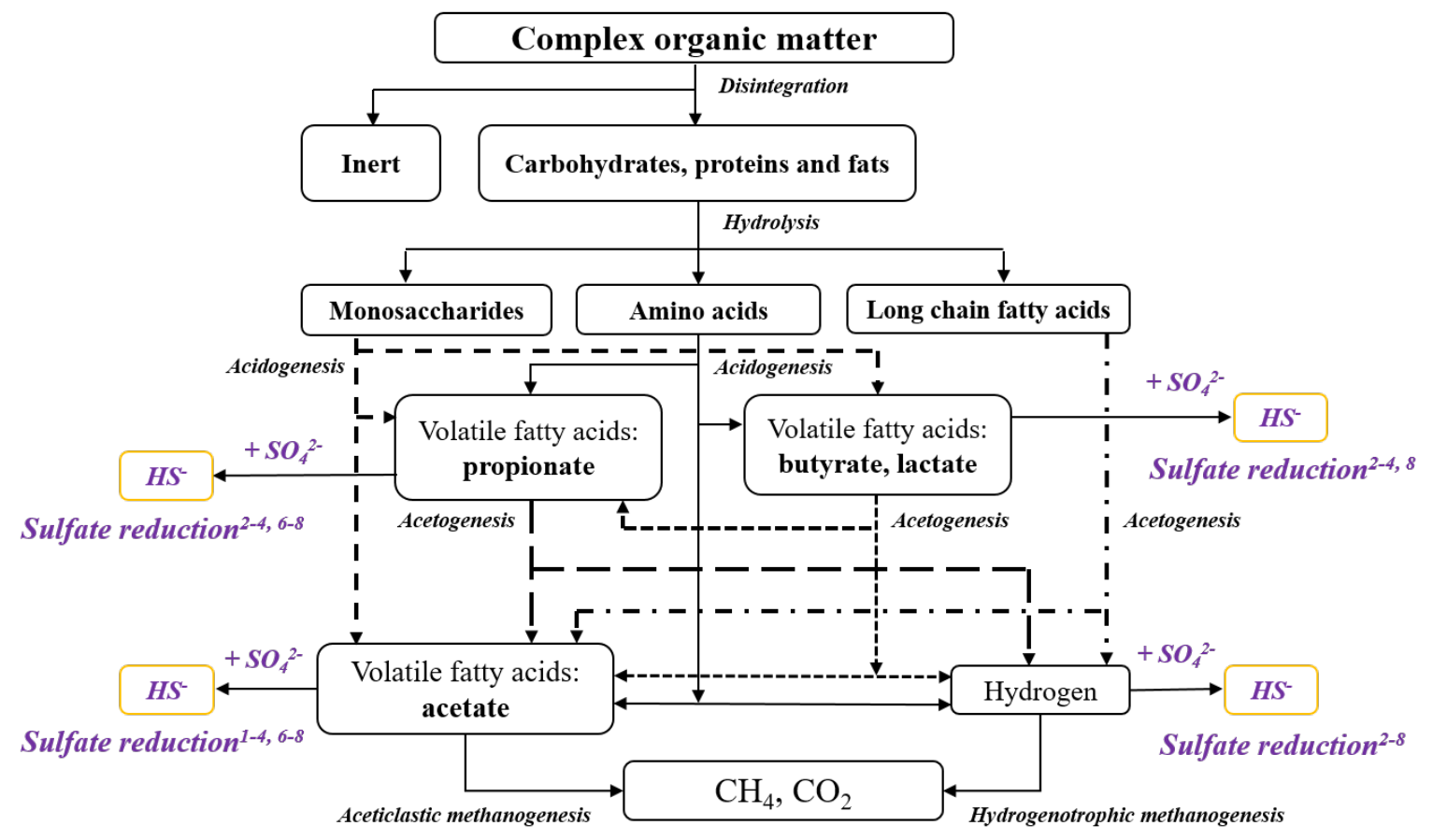

Figure 2. Schematic representation of the biochemical processes included in the model ADM1, including sulfate-reducing processes modelled by different authors. ${ }^{1}$ (Fomichev and Vavilin, 1997); ${ }^{2}$ (Kalyuzhnyi et al., 1998); ${ }^{3}$ (Knobel and Lewis, 2002); ${ }^{4}$ (Fedorovich et al., 2003); 5 (Frunzo et al., 2012); 6 (Durán, 2013; Durán et al., 2017); ${ }^{7}$ (Barrera et al., 2015); ${ }^{8}$ (Ahmed and Rodríguez, 2018). 




Figure 3. Combining the biological model ADM1, SMP dynamics and a filtration model. $X_{i}(i=1: 7)$ is the biomass produced in the acidogenesis from sugars, acidogenesis from amino acids, acetogenesis from long chain fatty acids (LCFA), acetogenesis from propionate, acetogenesis from butyrate and valerate, aceticlastic methanogenesis and hydrogenotrophic methanogenesis, respectively. 
A
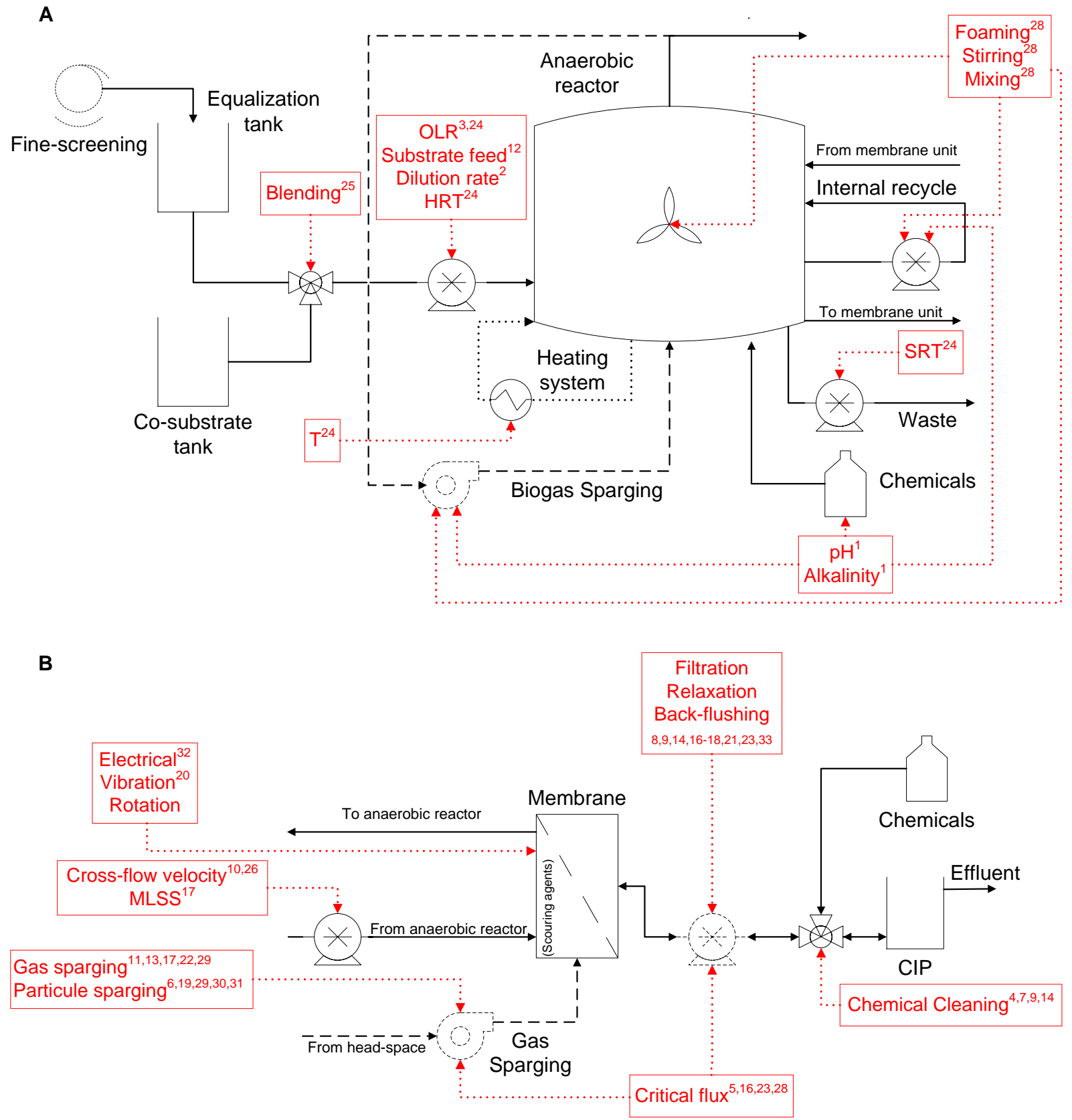

Figure 4. Main variables used in AnMBR technology for controlling: (a) the biological process and (b) the filtration process. 1(Marsili-Libelli and Beni, 1996); 2(Alvarez-Ramirez et al., 2002) ; ${ }^{3}$ (Holubar et al., 2003); '(Baek and Pagilla, 2006); 5 (Jeison and van Lier, 2006); ${ }^{6}$ (Hu and Stuckey, 2007) ; ${ }^{7}$ (Zhang et al.,


Diéguez et al., 2011) ; ${ }^{13}$ (Huang et al., 2011); ${ }^{14}$ (Kim et al., 2011); ${ }^{15}$ (Robles et al., 2012a, 2012b); ${ }^{16}$ (Cristea et al., 2013); ${ }^{17}$ (Robles et al., 2013a, 2013c, 2013b); ${ }^{18(V i l l a r r o e l ~ e t ~ a l ., ~ 2013) ; ~}{ }^{19}$ (Aslam et al., 2014); ${ }^{20}$ (De Vrieze et al., 2014); ${ }^{21}$ (Vera et al., 2014); 22 (Fox and Stuckey, 2015); ${ }^{23(P a u l e n ~ e t ~ a l ., ~ 2015) ; ~}$ 24(Jimenez et al., 2015); ${ }^{25}$ (Capson-Tojo et al., 2016); ${ }^{26}$ (Hu et al., 2017); ${ }^{27}$ (Mahmoud and Liao, 2017); ${ }^{28}$ (Pezzolla et al., 2017); ${ }^{29}$ (Zhang et al., 2017a); ${ }^{30}$ (Zhang et al., 2017b); ${ }^{31}$ (Charfi et al., 2018b); ${ }^{2}$ (Ding et al., 2018); ${ }^{33}$ (Kalboussi et al., 2018). 